\title{
Inoculum Dynamics and Infection of Citrus Fruit by Phyllosticta citricarpa
}

\author{
Nga T. Tran,,$^{1, \dagger}$ Andrew K. Miles, ${ }^{1}$ Ralf G. Dietzgen, ${ }^{2}$ Timothy A. Shuey, ${ }^{1}$ Stephen R. Mudge, ${ }^{1}$ Dan Papacek, ${ }^{3}$ \\ Kerri A. Chandra, ${ }^{4}$ and André Drenth ${ }^{1}$ \\ ${ }^{1}$ Centre for Horticultural Science, Queensland Alliance for Agriculture and Food Innovation (QAAFI), The University of Queensland, \\ Ecosciences Precinct, Dutton Park 4102, Queensland, Australia \\ ${ }^{2}$ Centre for Horticultural Science, QAAFI, The University of Queensland, Queensland Bioscience Precinct, St. Lucia 4072, Queensland, \\ Australia \\ ${ }^{3}$ Bugs for Bugs, Glenvale 4350, Queensland, Australia \\ ${ }^{4}$ Queensland Department of Agriculture and Fisheries, Ecosciences Precinct, Dutton Park 4102, Queensland, Australia \\ Accepted for publication 20 May 2020.
}

\begin{abstract}
Citrus black spot, caused by Phyllosticta citricarpa, is characterized by fruit blemishes and premature fruit drop, resulting in significant economic losses in summer rainfall areas. The pathogen forms both conidia and ascospores during its life cycle. However, the occurrence of these spores and their contributions to infection of fruit in field conditions are not well understood. Our research using direct leaf litter monitoring and volumetric spore trapping in Queensland orchards revealed that pseudothecia and ascospores in leaf litter as well as trapped ascospores had low abundance, while pycnidia and conidia were highly abundant. Both P. citricarpa and endophytic Phyllosticta spp. were identified, with $P$. citricarpa being dominant. In replicated field trials, we determined

conditions. These results demonstrate that protecting fruit during weeks 4 to 16 significantly reduced $P$. citricarpa infection. We found no significant correlation between the disease incidence in fruit and $P$. citricarpa conidial abundance in leaf litter or ascospore abundance measured by volumetric spore trapping. Therefore, it is suggested that inoculum sources in the tree canopy other than those detected by spore trapping and direct leaf litter monitoring may play a major role in the epidemiology of citrus black spot. Improved knowledge regarding epidemiology of $P$. citricarpa and an understanding of propagules causing infection may aid in development of more effective disease management strategies.
\end{abstract} that infection of Imperial mandarin fruit by $P$. citricarpa occurred from fruit set until week 20 of fruit development, with the key infection events taking place between weeks 4 and 16 in Queensland subtropical
Keywords: aerial dispersal, disease control, disease cycle, ecology and epidemiology, Guignardia, spore trap
The fungal pathogen Phyllosticta citricarpa (McAlpine) Aa (synonym: Guignardia citricarpa Kiely) causes citrus black spot, an economically important disease of citrus (Lanza et al. 2018). The disease was first reported from Australia (Benson 1895) and was subsequently detected in many humid subtropical and tropical citrus production regions in Asia, Africa, South America, and North America (Brentu et al. 2012; Wang et al. 2016). Citrus black spot causes significant losses to the citrus industry due to premature drop of heavily infected fruit in the field, reduced economic value of blemished fruit, and restricted market access (Brentu et al. 2012).

Symptoms of citrus black spot are expressed in different ways, including hard spot, freckle spot, and virulent spot (Kiely 1948). Hard spot is the classic symptom type, characterized by discrete, small, sunken lesions ( 3 to $5 \mathrm{~mm}$ in diameter) with dark margins and, typically, a light-tan to gray center, often containing pycnidia

†Corresponding author: N. T. Tran; n.tran3@uq.edu.au

Funding: N. T. Tran was sponsored by The University of Queensland through Ernest Singer Ph.D. and University of Queensland International scholarships. Funds have also been provided by the Citrus Research and Development Foundation and University of Florida (grant 715), Hort Innovation (grant CT13021), and Research and Development for Primary Industries Ptd. Ltd. This research was jointly supported by the Queensland Department of Agriculture and Fisheries and the University of Queensland through the Queensland Alliance for Agriculture and Food Innovation.

*The $e$-Xtra logo stands for "electronic extra" and indicates one supplementary figure is published online.

The author(s) declare no conflict of interest.

(c) 2020 The American Phytopathological Society
(Kiely 1948; Schubert et al. 2012). Freckle spot is also a common symptom type, described as small, red, depressed lesions usually 1 to $3 \mathrm{~mm}$ in diameter, which sometimes contain pycnidia (Brentu et al. 2012; Kiely 1948). Virulent spot is commonly observed on heavily infected fruit toward the end of the season or postharvest, expressing as spreading, sunken, necrotic lesions without a defined border that cover large areas of the fruit surface (Brentu et al. 2012; Kiely 1948).

P. citricarpa has been reported to infect citrus fruit up to 30 weeks from fruit set followed by a long latent period of up to 24 weeks (Kiely 1948; Lanza et al. 2018), which has hindered the development of disease control options. Disease control at present is almost entirely dependent on calendar-scheduled applications of protectant fungicides such as dithiocarbamate-based (e.g., mancozeb) or copper-based products during the fruit susceptibility period, which itself also varies among varieties of citrus (Baldassari et al. 2006; Miles et al. 2004; Schutte et al. 2003; Spósito et al. 2008). The effectiveness of these fungicide applications remains unknown until the end of the season, after the latent period, when symptoms are visibly expressed on the fruit. Intensive use of fungicides is costly and may lead to fungicide residues on fruit (Cunningham and Harden 1998). Moreover, copper products can cause rind stippling and darkening of preexisting blemishes on fruit (Schutte et al. 1997), while mancozeb is highly toxic to the predatory mite Amblyseius victoriensis used for biological control of the pest mites Tegolophus australis and Phyllocoptruta oleivora (Smith and Papacek 1991). Therefore, more accurate determination of $P$. citricarpa infection timing may be useful to improve control of citrus black spot in a more sustainable and cost-effective manner.

$P$. citricarpa reproduces sexually through the formation of ascospores in pseudothecia and asexually through the production of 
conidia in pycnidia. The pathogen also forms spermagonia, which produce spermatia that act as male gametes in sexual reproduction of $P$. citricarpa (Tran et al. 2017). These three spore types and fruiting bodies are formed readily in leaf litter. However, the seasonal dynamics of different spore types relative to one another and their roles in the epidemiology of citrus black spot are poorly understood. A clearer understanding of these aspects could be beneficial in predicting the availability and level of inoculum over time and in disease management through reducing sources of inoculum.

The relationship between the development of reproductive structures of Phyllosticta spp. and infection of fruit has been the topic of several studies. For example, it has been hypothesized that ascospores play a greater role than conidia in the epidemiology of citrus black spot (Fourie et al. 2013; Kiely 1948; McOnie 1964b). However, a number of observations suggest that the relative importance of the different spore types may vary depending on specific local conditions. In South Africa and Australia, ascospores are thought to be the main inoculum source due to the availability of airborne ascospores produced from leaf litter (Carstens et al. 2017; Tran et al. 2017). In contrast, opportunities for spread via waterdispersed conidia from mature symptomatic fruit to young susceptible fruit are limited in early-maturing varieties, where fruit is harvested prior to flowering of the subsequent crop (Fourie et al. 2013; Kiely 1948). In Florida, the observed disease progress is driven solely by conidia because only one mating type is present, preventing the opportunity for production of ascospores through sexual reproduction (Carstens et al. 2017; Wang et al. 2016). Epidemiological studies in Brazil provided evidence for conidia on fruit, leaves, and dead twigs as the main cause of epidemics, including aggregation of diseased fruit in the tree canopy, which was indicative of short-distance-dispersed conidia infecting the fruit (Spósito et al. 2007, 2008, 2011). Removal of leaf litter containing ascospores and conidia from the orchard floor failed to reduce the level of disease, whereas incidence of conidia on diseased fruit that overlap with next season's young fruit in the tree canopy was correlated with increased disease in the consecutive season (Spósito et al. 2011). The epidemiological contributions of conidia and ascospores may also be affected by their ability to cause disease on different varieties of citrus. Our previous study found that disease incidence and severity caused by ascospores and conidia in glasshouse conditions were comparable (Tran et al. 2018). However, the relative contributions of ascospores and conidia to epidemics of citrus black spot in different environmental conditions in the field are unknown.

Because ascospores, conidia, and spermatia of $P$. citricarpa are readily formed in leaf litter, a number of earlier studies examined leaf litter as a source of inoculum in the field (Kiely 1948; McOnie 1964b). In addition, volumetric spore traps have been used to monitor ascospores released from leaf litter to estimate the risk of infection over time as a tool to aid disease management decisions (Fourie et al. 2013; McOnie 1964b; Reis et al. 2006). Apart from the common sources of experimental variations and counting inefficiencies (Comtois et al. 1999; Hirst 1952), spore trapping studies of Phyllosticta spp. ascospores also face the challenge of other Phyllosticta spp. present in citrus orchards. These include the endophytes $P$. capitalensis, $P$. citribraziliensis (Glienke et al. 2011), and $P$. paracapitalensis and, potentially, the pathogenic P. paracitricarpa (Guarnaccia et al. 2017). In Australia, only the three species $P$. citricarpa, $P$. capitalensis, and $P$. paracapitalensis are known to occur on citrus (Miles et al. 2013; Tran et al. 2019). It is difficult to distinguish the different species morphologically based on ascospores, particularly in the case of $P$. capitalensis, which may be highly abundant due to its homothallic nature, common occurrence, and well-documented coexistence with $P$. citricarpa at high population levels in citrus (Glienke et al. 2011; Guarnaccia et al. 2017; Wang et al. 2016). However, most epidemiological studies of $P$. citricarpa ascospores (Fourie et al. 2013; Kiely 1948;
McOnie 1964b, 1967; Reis et al. 2006) occurred prior to the recent taxonomic clarifications of Phyllosticta spp. associated with citrus, and prior to the development of tools to readily distinguish between these species. As a consequence, previous ascospore trap data might be based on mixed Phyllosticta populations with unknown proportions of the pathogen and the endophytes, which makes interpretation of this data challenging. Moreover, among the studies reporting the importance of ascospores (Fourie et al. 2013; Kiely 1948; McOnie 1964b, 1967; Reis et al. 2006), only a few linked the ascospore release data to observed infection events or disease development with different outcomes (McOnie 1964b; Reis et al. 2006). Although Reis et al. (2006) found no relationship between severity of citrus black spot with numbers of ascospores, McOnie (1964b) found that time of fruit infection coincided with ascospore release.

In Australia, and particularly in the major mandarin-growing regions in subtropical areas of Queensland such as the North Burnett district (Hancock 2014), the seasonal dynamics of $P$. citricarpa reproductive structures and their correlations to fruit infection have not been studied in detail. Past studies, while still recognized as critical to current citrus black spot knowledge, were conducted on sweet orange varieties with potential for overlapping crops (Kiely 1948). In addition, Kiely (1948) conducted studies in specific coastal regions of New South Wales with a subtropical climate characterized by typically higher rainfall and humidity than North Burnett (Anonymous 2019; Peel et al. 2007). Hence, the role that each inoculum source of $P$. citricarpa plays in citrus black spot epidemics in the specific subtropical conditions in Queensland is not well understood.

The overall objective of this study was to investigate the relationship between inoculum production of $P$. citricarpa and the development of citrus black spot on fruit in field conditions in subtropical Queensland, Australia. We specifically sought to determine (i) the temporal development of reproductive structures of Phyllosticta spp. in leaf litter throughout the fruit production season, (ii) the relative abundance of P. citricarpa and endophytic Phyllosticta spp. in leaf litter, (iii) the critical periods of infection of citrus fruit by $P$. citricarpa leading to expression of citrus black spot symptoms, and (iv) the relationship between inoculum availability and occurrence of critical infection periods. Understanding the relationship between spore production of $P$. citricarpa and the occurrence of citrus black spot on fruit is critical to the design of disease management strategies for more efficient and effective control of the disease.

\section{MATERIALS AND METHODS}

Temporal development of reproductive structures of Phyllosticta spp. in leaf litter. Leaf litter sampling, microscopy, and spore extraction. To determine the temporal development of reproductive structures (spermagonia, pycnidia and conidia, pseudothecia, and ascospores) of Phyllosticta spp., leaf litter samples were collected every 2 to 3 weeks from beneath the canopies of trees in a block of Valencia orange (Citrus sinensis) planted in 1959. The block, located near the township of Mundubbera $(-25.611816,151.261043)$, has a known history of citrus black spot epidemics and a high proportion of leaves with fruiting bodies of Phyllosticta spp. found during preliminary sampling. The block was sampled during the 2013-14, 2014-15, 2015-16, and 2016-17 fruit production seasons. In each season, except 2016-17, additional orchards were also sampled. These orchards were, in 2013-14, a block of Imperial mandarin (C. reticulata) planted in 1976 ( $-25.627877,151.506941)$; in 2014-15, a block of Washington Navel orange (C. sinensis) planted in $1978(-25.615044,151.474306)$ and a block of Arnold blood orange (C. sinensis) planted in 2006 ( $-25.598926,151.189857)$; and, in 2015-16, a block of Eureka lemon (C. limon) planted in 1999 $(-25.632486,151.243258)$. 
At each sampling date, in total, 600 leaves were sampled from the orchard floor of each block from October to April. The leaves were systematically sampled by taking 25 leaves from 24 arbitrarily selected individual trees, with the 24 trees representing 6 replicate trees for each of the four cardinal points (north, south, east, and west). At each tree, the 25 leaves were collected from within a 50$\mathrm{cm}^{2}$ area just inside the drip line of the canopy. The sampled leaves were each inspected under a dissecting microscope for signs of fruiting bodies typical of Phyllosticta spp. (Sutton and Waterston 1966). Leaves without fruiting bodies were counted, then subsequently discarded. Leaves with fruiting bodies were recorded and the portions of the leaves with fruiting bodies subsampled; then, wet mounts were made of at least 30 fruiting bodies (or 2 fruiting bodies from each leaf section) from each replicate and examined microscopically to identify and quantify spermagonia, pycnidia, and pseudothecia of Phyllosticta spp. present on the leaf tissue. Identification of Phyllosticta fruiting bodies was based on previous descriptions (Baayen et al. 2002; Sutton and Waterston 1966). The number of fruiting bodies that appeared typical of Phyllosticta spp. but lacked any spermatia, conidia, or ascospores to confirm the type of fruiting body were recorded as undetermined, and proportions of each Phyllosticta fruiting body type were calculated based on the total number of fruiting bodies, including those recorded as undetermined.

Spores were extracted from leaves collected in all years except 2016-17. The leaf samples with fruiting bodies from a single tree for each cardinal position were pooled to give six replicate batches. In 2013-14, leaves were pooled from two trees for each cardinal position to give three replicated batches of leaves. Spore extraction from leaves began by first removing surface contaminants on the leaf tissue by washing thoroughly with tap water using a kitchen sieve to prevent loss of the leaf tissue. To stimulate ascospore ejection, the washed leaf tissue was placed into a beaker containing $40 \mathrm{ml}$ of sterile distilled water (SDW) at $40^{\circ} \mathrm{C}$, partially submerged in a water bath at $40^{\circ} \mathrm{C}$ for $5 \mathrm{~min}$ (Truter et al. 2004). The leaf tissue was then removed and immediately placed with the fruiting bodies facing downward on a 6-mm plastic mesh covering a $90-\mathrm{mm}$ diameter Petri dish containing $20 \mathrm{ml}$ of SDW containing $0.02 \%$ Tween 20 (Sigma-Aldrich, Castle Hill, NSW, Australia). The leaves were left suspended over the Petri dishes at room temperature overnight to allow ascospores to be liberated into the water from any mature pseudothecia present. The bottoms of the Petri dishes were swept lightly with a paint brush to dislodge any ascospores. The water in the Petri dishes was transferred into individual 40-ml centrifuge tubes, and the tubes were set aside. The leaf tissue was then transferred to beakers and submerged in $40 \mathrm{ml}$ of SDW + $0.02 \%$ Tween 20 and incubated at room temperature for $30 \mathrm{~min}$ to allow conidia to be liberated from any mature pycnidia. The contents of the beakers were transferred to 40-ml centrifuge tubes via a $150-\mu \mathrm{m}$ sieve, then a $38-\mu \mathrm{m}$ sieve, to remove debris from the spore suspension. All spore suspensions were then centrifuged at $1,150 \times g$ for $30 \mathrm{~min}$ to sediment the spores. All but approximately 1 to $2 \mathrm{ml}$ of the supernatant was pipetted off and discarded, and the spores were resuspended using a pipette before transfer to 2-ml microfuge tubes. To wash the spores, the tubes were centrifuged for 5 min at 2,350 $\times g$ to sediment the spores and the supernatant was removed; then, the spores were resuspended in $1 \mathrm{ml}$ of SDW before sedimenting the spores a second and third time before returning the volume of the spore suspension to $0.1 \mathrm{ml}$. The quantity of conidia and ascospores was determined using a hemacytometer. The leaf tissue from which spores were collected was dried for $72 \mathrm{~h}$ in an oven at $50^{\circ} \mathrm{C}$, then temporarily stored in a paper envelope. The paper envelopes and spore suspensions were stored at $-20^{\circ} \mathrm{C}$ until DNA extractions were undertaken.

Volumetric spore trapping. In order to determine the aerial release of Phyllosticta ascospores from leaf litter, a volumetric SporeWatch Sampler (Burkard Scientific Ltd., Uxbridge, Middlesex, U.K.) was used to trap ascospores in the orchard. The spore trap was operated continuously from September (approximately 4 weeks prior to fruit set in the 2015-16 season) or October (approximately at fruit set in the 2016-17 season) through to April (approximately 28 weeks after fruit set) in the same Valencia block of trees from which leaf litter samples were taken. The spore trap was located on the end of a row in place of a missing tree, surrounded on three sides by Valencia trees, and on the fourth side was an Imperial mandarin block (C. reticulata) grafted onto Benton citrange rootstock $(P$. trifoliata $\times C$. sinensis $)$, planted in 2009 $(-25.6117417,151.2627750)$, that was used for our "timing of infection" experiments. A narrow roadway separated the spore trap from the Imperial trees at a distance of approximately $10 \mathrm{~m}$.

The spore trap was positioned with the orifice $0.5 \mathrm{~m}$ above the orchard floor. Spores were trapped onto a rotating drum covered with 345-mm-long Melinex tape which was coated with silicon compound DM (Jet-Lube, Inc., Houston, TX, U.S.A.). While the drum was rotating, the vacuum fan drew air in at a rate of 10 liters/ min. The rotating speed of the drum was set for one rotation per week. Each week, the used drum was replaced with a clean drum and tape, and transported to the laboratory for Phyllosticta ascospore identification and quantification.

Statistical analysis. In order to determine whether the proportions of leaves with fruiting bodies were significantly influenced by time, cardinal position, or the time-cardinal position interaction, the data were analyzed by one- and two-way analysis of variance (ANOVA) using GenStat 16th edition statistical software (VSN 2013). To show the temporal development of Phyllosticta spp. in the leaf litter during the period of fruit susceptibility, the relative proportions of the different fruiting bodies and the associated spore yields from the corresponding leaf litter tissue of every 4 weeks were pooled and then plotted against time. The relationship between the proportions of pycnidia and pseudothecia and the spore yields of conidia and ascospores, respectively, was explored by simple linear regression analyses using GenStat. The analyses were done for the data from each season individually and combined. Response variate was number of conidia or ascospores, which were log-transformed to stabilize the variance before the analyses, while the explanatory variate was proportions of pycnidia or pseudothecia, respectively. Regression analysis was also undertaken to test the relationship between number of ascospores measured by volumetric spore trapping and proportions of pseudothecia of the total Phyllosticta fruiting bodies measured by direct leaf litter monitoring.

Relative abundance of pathogenic and endophytic Phyllosticta spp. Identification of fruiting bodies and spores obtained from leaf litter using quantitative PCR. In order to determine the relative abundances of pathogenic and endophytic Phyllosticta spp., total genomic DNA (gDNA) was extracted from the leaf tissue samples for use in quantitative PCR (qPCR). An 8mm-diameter biopsy punch was used to take discs of leaf tissue from samples processed above. Typically, 2 discs were collected from each of five leaves, and these 10 discs (approximately 30 to $40 \mathrm{mg}$ dry weight) were placed in a $2-\mathrm{ml}$ conical screw-cap tube with a 5-mm-diameter steel ball. Samples were subsequently frozen at $-80^{\circ} \mathrm{C}$ overnight in a TissueLyser adapter (Qiagen, Hilden, Germany), then ground to a powder using the TissueLyser $(2 \times 30 \mathrm{~s}$ at $24 \mathrm{~Hz}$ ) without letting the samples thaw. DNA was extracted from this ground tissue using the PowerSoil DNA Isolation Kit (MoBio Laboratories, Carlsbad, CA, U.S.A.).

Primers and probes for qPCR were as described (Hu et al. 2014), except that the probes included an internal quencher in addition to the $3^{\prime}$ quencher and 5' label (GCITSP1: 5' -6-FAM-AGCCGCCCGZEN-ACCTACCTTCA-Iowa black FQ-3' and GMITSP1: 5'HEX-CGCTACAAC-ZEN-GCCGAAATGACCTTCT-Iowa black FQ-3'). Both of these were PrimeTime probes synthesized by Integrated DNA Technologies (Baulkham Hills, NSW, Australia). The qPCR assays were done in a $10-\mu$ reaction volume using the QuantiTect Multiplex PCR Kit (Qiagen) containing $2 \mu$ of gDNA (nuclease-free water served as a nontemplate control), $5 \mu \mathrm{l}$ of 
$2 \times$ QuantiTect master mix, $0.4 \mu \mathrm{l}$ of each $10 \mu \mathrm{M}$ primer, $0.2 \mu \mathrm{l}$ of $10 \mu \mathrm{M}$ probe, and $2 \mu \mathrm{l}$ of nuclease-free water. The following conditions were used in a Rotor-Gene 6000 thermal cycler (Qiagen): $95^{\circ} \mathrm{C}$ for $10 \mathrm{~min}$ and 59 cycles of $94^{\circ} \mathrm{C}$ for $15 \mathrm{~s}$ and $59^{\circ} \mathrm{C}$ for $1 \mathrm{~min}$. Fluorescence was measured in the green and yellow channels for P. citricarpa and Phyllosticta endophytic species, respectively. Separate reactions were done with each set of primers and probes rather than duplex reactions, to avoid template concentration-dependent inhibition effects ( $\mathrm{Hu}$ et al. 2014). A standard curve consisting of serial 10-fold dilutions from $2.5 \mathrm{ng}$ to $2.5 \mathrm{fg}$ of gDNA was included in every qPCR assay. These standard curves used gDNA from $P$. citricarpa isolate BRIP 53711 and P. paracapitalensis isolate BRIP 54242, both extracted using a Wizard Genomic DNA Purification Kit (Promega Corp., Madison, WI, U.S.A.).

Because the primer and probe sequences (Hu et al. 2014) were published prior to the report of the endophytic species $P$. paracapitalensis in Queensland (Tran et al. 2019), the qPCR assay was applied to DNA from a population of 24 Australian endophytic Phyllosticta spp. isolates prior to deploying the qPCR for general Phyllosticta population studies. This was done to ensure that the genotypic diversity of Phyllosticta spp. detected in previous studies (Miles et al. 2013; Tran et al. 2019) did not result in isolates falling outside of the detection specificity of the qPCR primers. To further validate the assay, DNA extracted from citrus leaf litter in Florida, and previously characterized with the qPCR assay originally developed in Florida, was obtained and subjected to the assay to ensure reproducibility of results. Following these validation steps, the qPCR assay was used to determine the relative abundance of $P$. citricarpa and endophytic Phyllosticta spp. DNA in leaf litter samples collected from the study sites. In the context of the present study, the term "endophytic Phyllosticta spp." collectively refers to $P$. capitalensis, $P$. paracapitalensis, and possibly other endophytic Phyllosticta spp. that may occur on citrus in Queensland. When leaf litter samples showed more than $0.1 \%$ endophytic Phyllosticta spp., and the corresponding spore extraction samples had more than $10^{3}$ spores total (i.e., detectable limit of a hemocytometer), the qPCR assay was applied to the spore sample to determine the relative abundance of $P$. citricarpa and endophytic Phyllosticta spp. To extract DNA, the spore suspensions as sampled were incubated at $-80^{\circ} \mathrm{C}$ overnight, then transferred directly into a $65^{\circ} \mathrm{C}$ water bath for $10 \mathrm{~min}$, then vortexed for $3 \mathrm{~min}$ in the presence of 0.5-mm-diameter glass beads (Daintree Scientific, St. Helens, Tasmania, Australia). Subsequently, the tubes were centrifuged at $16,000 \times g$ for $1 \mathrm{~min}$ to sediment the glass beads and debris, and the supernatant was used for qPCR.

Identification and quantification of ascospores recovered by volumetric spore trapping. In the laboratory, the spore trap tape was removed from the drum and inspected visually. Where no obvious bands had formed from a high density of airborne materials collected on the tape, ascospores were identified and quantified microscopically using the following method. The tape was cut into seven 48-mm-long strips representing $24 \mathrm{~h}$ of trapping. All of the 24-h tapes were then stained with cotton blue in lactic acid (1:600 [wt/vol]) (Fourie et al. 2013) and the number of ascospores was counted on the entire tapes using an Eclipse Ci-L compound microscope (Nikon Corporation) at $\times 100$ magnification. Ascospores of Phyllosticta spp. were identified morphologically based on the description of Sutton and Waterston (1966) and Baayen et al. (2002).

In cases where obvious bands of trapped airborne materials were apparent, visual spore counts could not be reliably made due to an excess of airborne debris impacting on the tape. This occurred during the 2016-17 season for the following weeks from fruit set: from weeks 4 to 6 ( 10 to 29 November), weeks 18 to 25 (17 February to 13 April), and week 27 (20 to 27 April). The portions of tape without the bands were stained and visually inspected as described above, and qPCR assays were done on the unstained airborne debris bands of the tape to identify and quantify the presence of DNA of the pathogenic $P$. citricarpa and endophytic Phyllosticta spp.

For qPCR, the tapes were cut into small pieces of approximately $3 \times 3 \mathrm{~mm}$ and placed into $1.5-\mathrm{ml}$ microfuge tubes containing $100 \mu \mathrm{l}$ of deionized water and $0.5-\mathrm{mm}$-diameter glass beads. DNA extraction and qPCR were done as described for the spore suspensions obtained from leaf litter.

Converting qPCR data to numbers of ascospores. In order to compare data for ascospores obtained from the microscopic and qPCR quantification, qPCR data were converted from amount of gDNA present to number of ascospores. The quantity of gDNA for the different Phyllosticta spp. was extrapolated to the approximate number of ascospores based on the genome sizes of P. citricarpa and P. capitalensis (Wang et al. 2015). This was deemed appropriate because ascospores of all studied species are presumed to be single celled and to have four nuclei, based on their close genetic relationships with $P$. citricarpa (Guarnaccia et al. 2017; Hu et al. 2014). In addition, conidia of $P$. citricarpa have the same number of nuclei as those of $P$. capitalensis (Hu et al. 2014). Thus, the number of ascospores of $P$. citricarpa or endophytic Phyllosticta spp. were estimated separately using the formula: Number of ascospores = $\left[\mathrm{A}(\mathrm{pg}) \times 978\left(\mathrm{Mb} \mathrm{pg}^{-1}\right)\right] /[\mathrm{B}(\mathrm{Mb}) \times 4($ nuclei $)]$, where $\mathrm{A}=\mathrm{gDNA}$ of P. citricarpa or endophytic Phyllosticta spp. determined from qPCR assay and $\mathrm{B}=$ genome size of $P$. citricarpa $(31.56 \mathrm{Mb})$ or P. capitalensis $(32.45 \mathrm{Mb}$ ) (Wang et al. 2015).

Because visual quantification of ascospores could not distinguish the various Phyllosticta spp., the number of ascospores of the pathogenic and endophytic species obtained from qPCR data were combined. Total numbers of ascospores trapped per $24 \mathrm{~h}$ were converted to numbers of ascospores trapped per cubic meter of air.

Critical periods of citrus fruit infection by Phyllosticta citricarpa. Field sites and experimental design. To identify key $P$. citricarpa infection events on citrus fruit in orchard conditions, experiments were conducted over three seasons in two commercial orchards with a known history of citrus black spot in Mundubbera, Queensland. During the 2014-15 season, a field experiment was established in trees of the same midseason variety Arnold blood orange where the leaf litter was sampled. For the 2015-16 and 2016-17 seasons, experiments were conducted in trees of the earlyseason variety Imperial mandarin $(C$. reticulata) grafted onto Benton citrange rootstock ( $P$. trifoliata $\times C$. sinensis), planted in 2009 , and located on the fourth side of the spore trap surrounded on the other three sides by the Valencia trees.

Commencing at fruit set for a period of 16 (2014-15) or 24 (2015-16 and 2016-17) weeks, developing fruit were exposed to increasing periods of natural infection in approximately 4-weeklong increments. Mancozeb, an industry standard protectant fungicide (Schutte et al. 2003), was applied strategically to manipulate the exposure windows (treatments) of fruit to $P$. citricarpa infection. Details of treatments for each experiment are listed in Table 1, with each treatment including four single tree replicates assigned in a randomized complete block design along a single row of trees in each commercial orchard. Mancozeb (Penncozeb 750DF; Nufarm, Australia) was applied to individual trees at the product label rate $(2 \mathrm{~g} / \mathrm{liter})$ to the point of run-off (approximately 10 liters/tree) using a custom-built hand lance sprayer with dual D4 hollow cone nozzles, operating at approximately 3,500 Pa delivered by a 4.5-kW Robin EX17 gas enginedriven pressure pump (Subaru, Japan).

The first exposure window was created by leaving fruit untreated for the first 4 weeks after fruit set (defined as $75 \%$ petal fall), then commencing fungicide applications approximately every 4 weeks thereafter to prevent further infections. Subsequent windows of infection were then created by starting the fungicide applications progressively later. The process was repeated until the last treatment received only one fungicide application late in the season. Control fruit remained fully exposed (unsprayed) to confirm the presence of disease, while the control fruit for the effectiveness of the mancozeb 
treatment was fully protected by applications of mancozeb every 4 weeks for the entire season. To test whether early protection of fruit alone can prevent $P$. citricarpa infection, two treatments received either one or two early fungicide applications and remained unsprayed for the rest of the season were included. At fruit maturity in May (for Imperial mandarins) and June (for Arnold orange), approximately 50 fruit were harvested from each row-side of each data tree for a total of 100 fruit per tree $\times$ four replicate trees per treatment. In order to maximize symptom expression, fruit were then incubated for 3 weeks at $27^{\circ} \mathrm{C}, 80 \%$ relative humidity, and permanent light to break latency of $P$. citricarpa (Brodrick and Rabie 1970) before disease assessment.

Disease assessment. Disease incidence was defined as the percentage of fruit with black spot symptoms. Disease severity was defined as the level of disease on symptomatic fruit, which was measured as the number of lesions per fruit. We assessed discrete lesion types by counting the number of hard spot and freckle spot on each fruit. We assessed the spreading virulent spot by an estimate of the percentage of diseased surface area (\% virulent) which was then converted to an equivalent number of 3-mm-diameter lesions (number of lesions), which is the common size of the discrete lesions, using the formula: Number of lesions $=\%$ virulent $/[$ (SA3/ SA fruit) $\times 100$ ], where SA3 = surface area of a lesion $3 \mathrm{~mm}$ in diameter and $\mathrm{SA}$ fruit $=$ surface area of a fruit with mean radius $(\mathrm{R}=$ $28.3 \mathrm{~mm}$ ) of 20 randomly selected fruit of the citrus varieties studied. SA was calculated using the formula $S A=4 \pi R^{2}$. Overall disease severity of the symptomatic fruit was then calculated by adding together all numbers of lesions for all three symptom types.

Statistical analysis. Disease incidence and severity for each season were analyzed separately using GenStat. A generalized linear model with a binomial distribution and logit link was applied to the binomial incidence data. To determine whether treatments affect the severity of the disease in fruit with symptoms only, the clean fruit with 0 disease incidence were removed from the analysis; then, severity data were analyzed natural log-transformed to stabilize the variance. An unbalanced ANOVA was applied to the

TABLE 1. Schedules for treatments exposing citrus fruit to Phyllosticta citricarpa infection at different times during fruit development over three seasons-2014-15 (Arnold blood orange), 2015-16, and 2016-17 (Imperial mandarin)-in Mundubbera, Queensland

Timings of fungicide application (weeks after fruit set) ${ }^{\mathrm{b}}$

\begin{tabular}{lccccccc}
\cline { 2 - 7 } Exposure (weeks) & 0 & $4^{\mathrm{c}}$ & 8 & 12 & 16 & $20^{\mathrm{c}}$ & $24^{\mathrm{c}}$ \\
\hline Full protection & ++ & + & + & + & + & + & + \\
4 & $\rightarrow$ & ++ & + & + & + & + & + \\
8 & $\rightarrow$ & $\rightarrow$ & ++ & + & + & + & + \\
12 & $\rightarrow$ & $\rightarrow$ & $\rightarrow$ & ++ & + & + & + \\
16 & $\rightarrow$ & $\rightarrow$ & $\rightarrow$ & $\rightarrow$ & ++ & + & + \\
20 & $\rightarrow$ & $\rightarrow$ & $\rightarrow$ & $\rightarrow$ & $\rightarrow$ & ++ & + \\
24 & $\rightarrow$ & $\rightarrow$ & $\rightarrow$ & $\rightarrow$ & $\rightarrow$ & $\rightarrow$ & ++ \\
$4-24^{*}$ & ++ & $\rightarrow$ & $\rightarrow$ & $\rightarrow$ & $\rightarrow$ & $\rightarrow$ & $\rightarrow$ \\
$8-24^{*}$ & ++ & + & $\rightarrow$ & $\rightarrow$ & $\rightarrow$ & $\rightarrow$ & $\rightarrow$ \\
Full exposure & $\rightarrow$ & $\rightarrow$ & $\rightarrow$ & $\rightarrow$ & $\rightarrow$ & $\rightarrow$ & $\rightarrow$
\end{tabular}

a Duration of fruit exposure (weeks after fruit set). An asterisk (*) indicates that fruit were protected (sprayed) from start of the season until the indicated time and remained exposed (unsprayed) for the rest of the season.

b The experiment in the 2014-15 season was conducted for only 16 weeks from fruit set, with dates for each of the fungicide (mancozeb) application timings being 2 October, 3 November, 8 December, 13 January, and 16 February. Dates for each of the timings of fungicide application in the 2015-16 season were 2 October, 28 October, 25 November, 18 December, 20 January, 18 February, and 16 March. In the 2016-17 season, dates of applications were 12 October, 4 November, 20 December, 18 January, 14 February, and 23 March. Symbols: $\rightarrow$ indicates duration of fruit exposure (unsprayed), ++ indicates first application, and + indicates reapplication of fungicide approximately every 4 weeks to protect fruit from natural infection by $P$. citricarpa.

c These treatments were not applicable to the 2014-15 season. severity data to account for the variable number of clean fruit removed from each treatment and the small but variable number of missing fruit resulting from decay (mold) during postharvest incubation. Where the number of symptomatic fruit was low, no ANOVA was performed and only the mean was presented. Replicates were included as a blocking factor and fruit exposure time was included as a treatment factor. To test the relationships between means, pairwise comparisons were performed for significantly different treatments $(P<0.05)$ using Fisher's least significant difference test.

Relationships between Phyllosticta inoculum availability and timing of fruit infection. Regression analyses. In order to determine the relationships between abundance of ascospores or conidia and level of disease in field conditions, linear regression analyses were done both separately and combined for the two seasons 2015-16 and 2016-17 using GenStat. The response variate was disease incidence resulting from each of the six 4-week-long periods of fruit exposure to $P$. citricarpa in the timing of infection experiments. The explanatory variate was the numbers of ascospores trapped for each 4-week-long period, or conidia recovered from leaf litter. Data were log-transformed to stabilize the variance before the analyses.

Estimation of numbers of ascospores required to cause the numbers of lesions observed. In order to test the hypothesis that ascospores were the main source of inoculum causing the disease on Imperial fruit in field conditions, disease incidence and severity resulting from each of the six 4-week-long periods of fruit exposure in the timing of infection experiments were converted to numbers of lesions that occurred on 100 fruit, which was the mean number of fruit assessed for each treatment in the timing of infection experiments, using the formula: Number of lesions/100 fruit $=$ disease incidence $(\%) \times$ disease severity (number of lesions/fruit).

To determine the potential number of ascospores available to infect 100 fruit, the numbers of ascospores trapped per cubic meter were first multiplied by the total volume of space occupied by 100 fruit to obtain the number of ascospores trapped/total volume of 100 fruit (cubic meters). Total volume of 100 fruit was calculated based on radius $(\mathrm{R})$ of Imperial mandarins being approximately $7.5,13.5$, $15.5,18.5,20.0$, and $28.5 \mathrm{~mm}$ for fruit at week 4, 8, 12, 16, 20, and 24, respectively (Hofman 2011), using the formula: Fruit volume $\left(\mathrm{m}^{3}\right)=\left[(4 / 3) \times \pi \times \mathrm{R}^{3}\right] \times 100$ fruit. Because only the fruit surface can be infected by ascospores, the numbers of ascospores potentially occupying the same space as 100 fruit were then divided by the corresponding surface area of 100 fruit to give the number of ascospores per square meter of fruit. Fruit surface areas were determined using the formula: Fruit surface area $\left(\mathrm{m}^{2}\right)=\left[\left(4 \times \pi \times \mathrm{R}^{2}\right]\right.$ $\times 100$ fruit.

To test whether the numbers of Phyllosticta ascospores released from leaf litter are of sufficient quantity to cause the numbers of lesions observed in the field during each 4 -week-long period of fruit exposure to $P$. citricarpa infection, we assumed that one lesion of citrus black spot is caused by one ascospore; thus, numbers of lesions observed were the numbers of ascospores required to cause all of the observed lesions. In addition, we assumed that operation of the spore trap and quantification of ascospores were fully efficient, all of the ascospores trapped were viable and virulent, and environmental conditions were evenly favorable for infection of ascospores for every 4-week-long period of fruit exposure, leading to successful infection. Thus, disease expression of every single ascospore trapped was assumed to be possible.

\section{RESULTS}

Temporal development of reproductive structures of Phyllosticta spp. in leaf litter. Analysis of the proportions of leaves with fruiting bodies showed that, in most years, in most sites, the sampling time, cardinal position, and sampling time $\times$ cardinal position interactions were significant $(P<0.05)$. However, no single 
such factor was identified as being consistently more or less likely to have a significantly different proportion of leaves with fruiting bodies across all years and trial sites (data not shown). Fruiting bodies formed in leaf litter as observed under the microscope were in different stages of development, which resulted in a large proportion of the fruiting bodies that could not be confidently designated as pseudothecia, spermagonia, or pycnidia. This undetermined proportion has been excluded from Figure 1 and Supplementary Figure S1.

Observations of the temporal development of reproductive structures of Phyllosticta spp. in leaf litter from the long-term study site of Valencia orange showed the production of spermagonia to be variable throughout the study period each year, with no welldefined peak at any point in time (Fig. 1A to C). The production of pycnidia was similar but with a clear peak at the beginning of the season in all years (Fig. 1D, E, and G), except 2015-16, when the production of pycnidia fluctuated throughout the season (Fig. 1F). The relative abundance of pseudothecia tended to peak in the middle of the fruit season (i.e., between weeks 9 and 12 for 2013-14, weeks 13 and 16 for 2014-15, and weeks 17 and 20 for 2015-16) (Fig. $1 \mathrm{H}$ to $\mathrm{K}$ ). In 2016-17, the abundance of pseudothecia (and spermagonia and pycnidia) was low relative to the other years, with a small increase in pseudothecia late in the fruit season (Fig. 1K).

Observations of the seasonal dynamics of Phyllosticta spp. in leaf litter from the other sites-Imperial mandarin, Arnold blood orange, Washington Navel orange, and Eureka lemon-showed trends similar to those at the Valencia orange site. In particular, the spermagonia (Supplementary Fig. S1A to C) and pseudothecia (Supplementary Fig. S1H to K) data, the latter also showing peaks in pseudothecium production in the middle of the seasons, were similar to those observed at the Valencia site. The production of pycnidia did not show the same tendency for a clear peak early in the season as was observed for the Valencia orange but, rather, the relative abundance of pycnidia fluctuated across the season (Supplementary Fig. S1D to G).

Spore harvesting directly from leaf litter across all sites showed that the yields of conidia generally were related to the relative abundance of pycnidia (Fig. 1; Supplementary Fig. 1). A similar pattern was observed for ascospores and pseudothecia but to a less obvious extent. Regression analysis of each season separately and of the combined data for all seasons indicated that the correlations between pycnidia and conidia, pseudothecia, and ascospores were significant $(P<0.05)$ (Table 2$)$.

Ascospore release as measured by volumetric spore trapping varied between the two studied seasons, with higher frequency and quantity of ascospores trapped in the 2015-16 season than in the following season (Fig. 1J and K; Table 3). In 2015-16, no ascospores were observed during the 4-week-long period prior to fruit set (Fig. 1J; Table 3). The first ascospore release event was approximately at fruit set (early October), after which ascospores were trapped intermittently on a weekly basis. On a 4-week-period

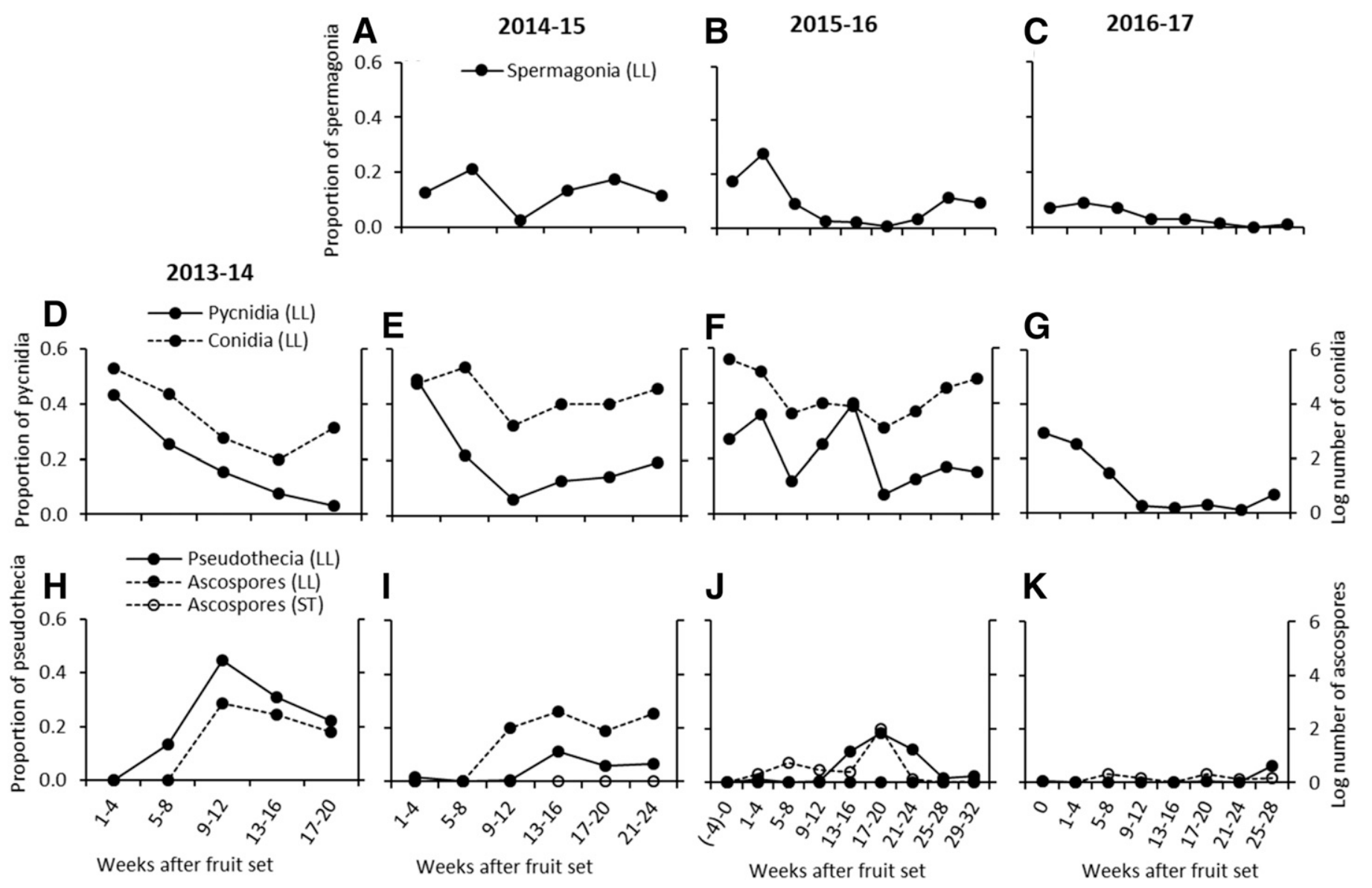

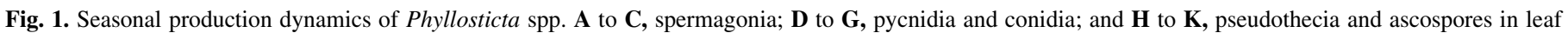

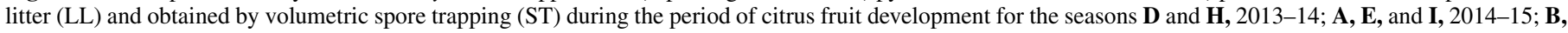

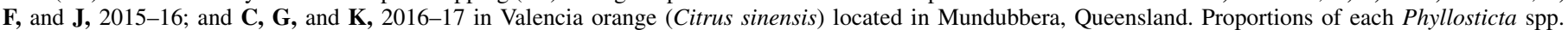

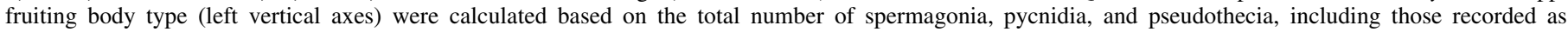

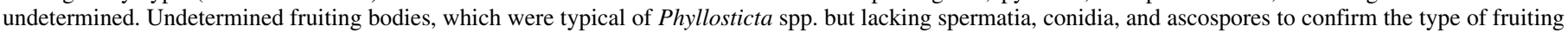

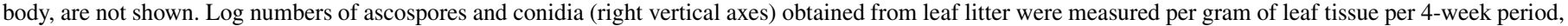
and ascospores obtained by spore trapping were calculated per cubic meter of air per 4-week period. 
basis in line with our timing of infection experiments, the total number of ascospores trapped ranged from 1.1 to 4.6 ascospores/ $\mathrm{m}^{3} / 4$ weeks during weeks 0 to 16 . Ascospore release peaked during week 17 to 20, with 98.7 ascospores $/ \mathrm{m}^{3} / 4$ weeks (Table 3). Only 0.3 ascospores $/ \mathrm{m}^{3}$ were captured for the 4-week period of week 21 to 24 , after which no more ascospores were trapped (Table 3). In 2016-17, combined numbers of ascospores from visual counts and qPCR showed a general trend that ascospores were less frequently captured than in the preceding season (Fig. 1K; Table 3). No ascospores were trapped during the periods of weeks 5 to 8,13 to 16 , and 25 to 28. During the other 4-week-long periods, numbers of ascospores trapped were low at $\leq 1.1$ spores $/ \mathrm{m}^{3} / 4$ weeks (Table 3 ).

Timing of pseudothecium production in leaf litter and ascospore release measured by spore trapping showed a similar trend and peaked at the same time over the fruit susceptibility period for both seasons 2015-16 and 2016-17 (Fig. 1J and K). The correlation between pseudothecia in leaf litter and ascospores trapped for each single season in 2015-16 and 2016-17 was not significant but was significant for the combined data of the two seasons (Table 2).

Relative abundance of $P$. citricarpa and endophytic Phyllosticta spp. The relative abundance of $P$. citricarpa and endophytic Phyllosticta spp. in leaf litter as determined by qPCR varied across the different study sites. The long-term Valencia study site consistently showed the lowest levels of Phyllosticta endophytes in all seasons, with the highest proportion being $1.3 \%$ of the total Phyllosticta DNA for the period of weeks 17 to 20 of the 2015-16 season; however, most 4-week-period samples contained $<0.4 \%$ (data not shown). The other study sites (i.e., Imperial, Washington Navel, Arnold, and Eureka) were similar to the Valencia site, whereby the majority of leaf litter samples had much lower levels of endophytic Phyllosticta spp. DNA than P. citricarpa. In the case of these other sites, the endophytic proportion generally represented $<17 \%$ of the total Phyllosticta DNA, with the only exception being the sample for weeks 9 to 12 of the Arnold site having 32\% endophytic Phyllosticta spp. (data not shown). In several cases, the proportion of the endophytes was highly variable among replicate samples at a particular time point and site. In extreme cases, replicate leaf litter samples could range from almost $100 \%$ endophytic Phyllosticta spp. to almost $100 \%$ P. citricarpa (data not shown). This variability among replicates was confirmed in multiple independent assays on different days.
In the application of the qPCR assay to the spore samples directly harvested from leaf litter to determine the relative abundance of P. citricarpa and the endophytic Phyllosticta spores, the recovery of ascospores from the leaf litter was generally extremely low, with the vast majority of samples yielding below the detectable limit of the hemacytometer. Therefore, in all cases, the spore analysis was done using conidial suspensions. In many cases, these water-extracted conidial suspensions also contained numerous spermatia, although these were not quantified in this study. In total, we assayed 39 spore suspensions by qPCR. As with the leaf litter samples, it was possible to amplify $P$. citricarpa DNA from every spore suspension tested but only approximately half of the suspensions (21 of 39) contained DNA of the endophytic species based on this assay (Fig. 2). Only one spore sample for 11 February 2015 at the Washington Navel site had endophytic Phyllosticta levels approaching those of P. citricarpa (47.3 and 52.7\%, respectively) (Fig. 2), and the corresponding leaf litter had more of the endophytic DNA $(60.2 \%)$ than $P$. citricarpa. High levels of the endophytes as measured by total gDNA in leaf litter did not always translate into their high levels in spore suspensions. For example, a conidial suspension contained only $7.8 \%$ endophytes but the corresponding leaf litter sample showed $80.6 \%$ of the endophytes by qPCR (data not shown).

Results of qPCR assays on ascospores trapped using the volumetric spore trap in the 2016-17 season showed no Phyllosticta spp. ascospores detected for the early period from weeks 4 to 6 , and week 25. Among six of eight weekly samples that had both P. citricarpa and endophytic Phyllosticta spp. detected, 5 weeks had P. citricarpa accounting for 73.7 to $100 \%$ of the total gDNA, and only week 22 had equal proportions of the two species (Fig. 3). Total Phyllosticta gDNA for these weeks ranged from 0.11 to $1.81 \mathrm{pg} /$ week. Week 21 had only P. citricarpa detected while week 24 had only the endophytes (Fig. 3), with relatively low gDNA quantities of approximately 0.05 and $0.01 \mathrm{pg}$, respectively.

Critical periods of citrus fruit infection by Phyllosticta citricarpa. Exposure of citrus fruit at various time periods to $P$. citricarpa infection resulted in significant differences $(P<0.001)$ in citrus black spot incidence and severity. In all three seasons, there were clear differences in the amount of citrus black spot between fully exposed and fully protected treatments, with the fully protected fruit showing the lowest level of disease incidence and severity (Fig. 4). In the 2014-15 season on Arnold orange, all

TABLE 2. Regression analyses of Phyllosticta fruiting body and spore numbers with fruit disease incidence of citrus black spot in orchard conditions in Mundubbera, Queensland

\begin{tabular}{|c|c|c|c|c|c|}
\hline $\begin{array}{l}\text { Regression models } \\
(\text { explanatory } \times \text { response variables })^{\mathrm{a}}\end{array}$ & Seasons & $P$ values ${ }^{\mathrm{b}}$ & $R^{2}(\%)$ & Constant & Slope \\
\hline \multirow[t]{2}{*}{ Pseu (LL) × Asc (LL) } & 2013-14 & 0.02 & 14.9 & 0.07 & 3.00 \\
\hline & $2014-15$ & 0.002 & 11.6 & 0.27 & 5.69 \\
\hline \multirow[t]{3}{*}{ Pseu (LL) $\times$ Asc $(\mathrm{ST})$} & 2015-16 & NS & $\ldots$ & $\ldots$ & $\ldots$ \\
\hline & 2016-17 & NS & $\ldots$ & $\ldots$ & $\ldots$ \\
\hline & Combined 2 seasons & 0.005 & 39.6 & 0.15 & 5.73 \\
\hline \multirow[t]{2}{*}{ Pyc $($ LL $) \times$ Con $(L L)$} & 2013-14 & 0.006 & 21.3 & 1.83 & 4.46 \\
\hline & Combined 3 seasons & $<0.001$ & 11.8 & 2.41 & 3.63 \\
\hline \multirow[t]{3}{*}{$\mathrm{DI} \times \operatorname{Asc}(\mathrm{ST})$} & $2015-16$ & NS & $\ldots$ & $\ldots$ & $\ldots$ \\
\hline & 2016-17 & NS & $\ldots$ & $\ldots$ & $\ldots$ \\
\hline & Combined 2 seasons & NS & $\ldots$ & $\ldots$ & $\ldots$ \\
\hline \multirow{3}{*}{ DI $\times$ Con $(L L)$} & $2014-15$ & NS & $\ldots$ & $\ldots$ & $\ldots$ \\
\hline & $2015-16$ & NS & $\ldots$ & $\ldots$ & $\ldots$ \\
\hline & Combined 2 seasons & NS & $\ldots$ & $\ldots$ & $\ldots$ \\
\hline
\end{tabular}

${ }^{a}$ Pseu $=$ pseudothecia, Asc $=$ ascospores, Pyc $=$ pycnidia, Con = conidia, DI = disease incidence, LL $=$ fruiting body or spore data collected from leaf litter, and $\mathrm{ST}=$ ascospores collected by volumetric spore trapping. Pseudothecia and pycnidia were measured as their proportions out of total number of Phyllosticta spp. fruiting bodies, including those typical of Phyllosticta spp. but lacking spermatia, conidia, and ascospores to confirm the type of fruiting body and, thus, recorded as undetermined; ascospores and conidia were measured as the numbers of spores; disease incidence was measured as percentage of fruit with citrus black spot symptoms. Data of fruiting body and spores were obtained from the Valencia orange block while disease incidence was from the nearby Imperial mandarin block, except that disease incidence and conidia from leaf litter for 2014-15 were from the Arnold orange block.

${ }^{\mathrm{b}} \mathrm{NS}=$ not significant $(P>0.05)$. 
treatments where mancozeb was applied had significantly lower $(P<0.001)$ disease incidence than the full-exposure control (Fig. 4A). The most significant increase in disease incidence for this season resulted from fruit exposed between fruit set and week 8, and between weeks 12 and 16. In the two later seasons (2015-16 and 2016-17 on Imperial mandarin), fruit exposed for the first 4 weeks from fruit set resulted in disease incidence similar to that of the fully protected fruit (Fig. 4C and E). During the period from weeks 4 to 20, any further 4-week-long exposure resulted in significant increase $(P<0.001)$ in disease incidence (Fig. $4 \mathrm{C}$ and $\mathrm{E})$. The most significant increase occurred when fruit was exposed between weeks 4 and 16, with each further 4-week exposure leading to a twoto threefold increase in disease incidence, and ninefold when fruit was exposed for 12 weeks compared with 8 weeks in the 2016-17 season (Fig. 4C and E). Although the 2014-15 trial ended in week 16 , additional exposure from weeks 16 to 20 in the 2015-16 season increased disease incidence by approximately $12 \%$, to reach the maximum disease incidence of $100 \%$. Therefore, further exposure of fruit beyond week 20 in the 2015-16 season did not further increase disease incidence (Fig. 4C). However, in the 2016-17 season, no increase in disease incidence was observed when fruit were exposed beyond week 20 (Fig. 4E).

The treatments of only one or two mancozeb sprays at fruit set and week 4, after which fruit were kept unsprayed, led to significantly reduced disease incidence compared with the fully exposed fruit. However, in the 2014-15 season, those two early sprays did not result in significant differences in disease incidence compared with fruit exposed until week 8 and 12 but significantly lowered $(P<0.001)$ the disease incidence compared with fruit exposed until week 16 (Fig. 4A). Likewise, in the 2016-17 season, the one or two early mancozeb applications resulted in significantly less $(P<0.001)$ disease incidence than that of fruit exposed for longer than 12 weeks after fruit set (Fig. 4E). In the 2015-16 season, although the early mancozeb applications did not result in substantial reduction of disease incidence (Fig. 4C), disease severity was statistically lower $(P<0.001)$ than that for the fully exposed and late protected fruit (i.e., from week 20 on) (Fig. 4D). In all three seasons, disease incidence generally reflected disease severity; that is, the higher the incidence, the greater the severity.

Overall, disease incidence and severity were higher in the 2015-16 season than in the 2014-15 and 2016-17 seasons. This was evident from the $100 \%$ disease incidence and the severity of 33 lesions/fruit for the fully exposed fruit of the 2015-16 season, compared with approximately 50\% incidence and $<6$ lesions/fruit for both the 2014-15 and 2016-17 seasons (Fig. 4).

Relationship between Phyllosticta inoculum availability and timing of fruit infection. Regression analyses between the numbers of ascospores trapped (calculated based on volumetric spore trap data) per surface area of fruit and disease incidence for each of the six 4-week-long periods of fruit exposure to $P$. citricarpa did not show a significant correlation, with $P>0.05$ for data of each individual season and the combined 2015-16 and 2016-17 seasons (Table 2). Similarly, no significant correlation was found between conidia produced in leaf litter and disease incidence for both individual and the combined 2014-15 and 2015-16 seasons (Table 2).

Numbers of ascospores trapped (volumetric spore trap) in the 2015-16 and 2016-17 fruit production seasons were very low compared with the spores required to produce the observed number of lesions. In the 2015-16 season, the highest number of ascospores trapped per surface area of 100 fruit was 0.7 for the period of weeks 17 to 20 after fruit set, which represented only $2.6 \%$ of that required to cause the observed number of lesions (Table 3 ). During the other 4 -week-long periods, the numbers were $<0.2$ ascospores trapped per surface area of 100 fruit, representing $<0.7 \%$ of that required. In the 2016-17 season, numbers of ascospores trapped per surface area of 100 fruit for all 4-week-long periods were $<0.1$, representing $0.3 \%$ of the spores required to cause the observed lesions. In both seasons, although the observed numbers of lesions (i.e., numbers of ascospores required) were highest during the periods of weeks 9 to 12 and 13 to 16 after fruit set, no ascospores were trapped or the numbers of ascospores trapped were lower than the following period of weeks 17 to 20 (Table 3).

\section{DISCUSSION}

Our results show that, in field conditions, pseudothecia and ascospores of Phyllosticta spp. were produced in relatively small quantities, with peaks observed after weeks 17 to 20 of citrus fruit development, whereas pycnidia and conidium production was often found to peak early in the season, then fluctuate thereafter. We demonstrated that the critical time of infection of Imperial fruit by $P$. citricarpa in field conditions was during weeks 4 to 16 of fruit development. Correlations between presence of reproductive structures, measured by direct leaf litter monitoring and volumetric spore trapping, and disease incidence were not statistically significant. As determined by qPCR, $P$. citricarpa was far more abundant than the endophytic Phyllosticta spp., indicating that the majority of reproductive structures we observed were those of the pathogen. Our data suggest that inoculum sources other than those detected by spore trapping and direct leaf litter monitoring play a major role in the epidemiology of citrus black spot in Queensland subtropical conditions.

Direct leaf litter examinations for production of fruiting bodies and spores of Phyllosticta spp. generally showed that spermagonia, pycnidia, and conidia were more frequently and more abundantly produced than pseudothecia and ascospores. Conidia and pycnidia were the most abundant spore and fruiting body type in citrus leaf

TABLE 3. Phyllosticta spp. ascospore release measured by volumetric spore trapping over 4-week-long periods compared with the theoretical numbers of ascospores required to cause the numbers of citrus black spot lesions resulting from the corresponding 4-week-long exposure period of Imperial mandarin fruit to Phyllosticta citricarpa infection in orchard conditions for the 2015-16 and 2016-17 fruit seasons in Mundubbera, Queensland

\begin{tabular}{|c|c|c|c|c|}
\hline $\begin{array}{l}\text { Duration of fruit } \\
\text { exposure (weeks } \\
\text { after fruit set) }\end{array}$ & $\begin{array}{l}\text { Asc } \\
\text { trapped/ } \\
\mathrm{m}^{3 \mathrm{a}}\end{array}$ & $\begin{array}{c}\text { Asc trapped/ } \\
\mathrm{m}^{2} \text { of } 100 \\
\text { fruit }^{\mathrm{b}}\end{array}$ & $\begin{array}{c}\text { Asc } \\
\text { required } / \mathrm{m}^{2} \\
\text { of } 100 \mathrm{fruit}^{\mathrm{c}}\end{array}$ & $\begin{array}{l}\text { Percent Asc } \\
\text { trapped/ } \\
\text { required }^{\mathrm{d}}\end{array}$ \\
\hline \multicolumn{5}{|l|}{ 2015-16 season } \\
\hline-4 to $-1^{e, f}$ & 0 & $\ldots$ & $\ldots$ & $\ldots$ \\
\hline 0 to 4 & 1.1 & $<0.01$ & 0.4 & 0.7 \\
\hline 5 to 8 & 4.6 & 0.02 & 4.0 & 0.5 \\
\hline 9 to 12 & 1.9 & $<0.01$ & 230.8 & $<0.01$ \\
\hline 13 to 16 & 1.4 & $<0.01$ & 41.7 & 0.02 \\
\hline 17 to 20 & 98.7 & 0.7 & 25.1 & 2.6 \\
\hline 21 to 24 & 0.3 & $<0.01$ & 3.5 & 0.08 \\
\hline 25 to $28^{f}$ & 0 & $\ldots$ & $\ldots$ & $\ldots$ \\
\hline \multicolumn{5}{|l|}{ 2016-17 season } \\
\hline 0 to 4 & 0.1 & $<0.01$ & 0 & $\ldots$ \\
\hline 5 to 8 & 0 & 0 & 1.6 & 0 \\
\hline 9 to 12 & 0.4 & $<0.01$ & 20.5 & 0.01 \\
\hline 13 to 16 & 0 & 0 & 76.2 & 0 \\
\hline 17 to 20 & 1.1 & 0.01 & 2.8 & 0.3 \\
\hline 21 to 24 & 0.3 & $<0.01$ & 0 & $\ldots$ \\
\hline 25 to $28^{f}$ & 0.4 & $\ldots$ & $\ldots$ & $\ldots$ \\
\hline
\end{tabular}

a Total number of Phyllosticta spp. ascospores obtained by volumetric spore trapping per cubic meter of air over 4-week-long periods.

b Calculated numbers of ascospores trapped per total surface area (square meters) of 100 fruit.

c Numbers of ascospores required to cause the total number of citrus black spot lesions on the surface area (square meters) of 100 fruit, with number of ascospores required equal to number of lesions based on the assumption that one $P$. citricarpa spore causes one lesion of citrus black spot on fruit.

d Percentage of ascospores trapped per surface area of 100 fruit to the ascospores required to cause the observed number of lesions on surface area of 100 fruit.

e Negative numbers indicate weeks before fruit set.

$\mathrm{f}$ These time periods were only included in spore trapping but not included in the timing of infection experiments. 
litter. As expected, the presence of fruiting bodies and their corresponding spores (pycnidia and conidia, pseudothecia and ascospores) was positively correlated. An initial peak in pycnidium formation early in the season was followed by relatively consistent production of pycnidia, whereas pseudothecium production occurred in more isolated peaks later in the season. This observation of the seasonal dynamics of pycnidium and pseudothecium production in leaf litter is consistent with previous research in Queensland (Miles et al. 2008).

A possible explanation for the initial peak in pycnidium production may be the early peak in mature leaf abscission that occurs in early spring, followed by a consistent, low level of abscission during the rest of the season (Erixckson and Brannaman 1960). During the peak of leaf abscission in spring, the environmental conditions (e.g., rainfall, temperature, and wetting and drying cycles) needed for pseudothecium production are unlikely to have occurred; however, such specific conditions are not necessary for pycnidium and spermagonium development to take place (Fourie et al. 2013; Kiely 1948). Hence, formation of pycnidia and spermagonia is more likely, more often. Pseudothecium formation in field conditions is reported to be associated with wetting and drying cycles driven by rainfall (Alvarez 2004; Kiely 1948; McOnie 1964a) but the reasons why these cycles are needed are unknown. Considering recent findings demonstrating that spermatia are capable of fertilizing complementary mating types, it would seem likely that the wetting part of the cycle creates an opportunity for spermatia to be liberated and disseminated to make contact with the compatible mating type (Tran et al. 2017). Furthermore, Tran et al. (2017) showed that mycelium of $P$. citricarpa colonies avoided growing into each other, likely precluding mating via mycelial interactions. For these reasons, it is likely that the observed defined peaks in pseudothecium production follow mating opportunities that are tightly confined to the onset of specific weather conditions, including wetting and drying.

We examined Phyllosticta ascospore production by volumetric spore trapping in addition to direct leaf litter monitoring, and found that ascospore release reflected pseudothecium production in leaf litter. That is, defined peaks of ascospore release were only observed when pseudothecium production peaked. In addition, there was a statistically significant correlation between the number of ascospores trapped and pseudothecia formed in leaf litter for the combined data of two seasons (2015-16 and 2016-17). The consistency of seasonal dynamics of Phyllosticta ascospore production obtained through the two independent measurements indicated reliability of the results. Nevertheless, numbers of ascospores trapped in the present study were relatively low and varied within and between seasons. In particular, from the 10-liters/ min spore trap we obtained $<5$ ascospores $/ \mathrm{m}^{3}$ for most of the 4week-long trapping windows in the 2015-16 season and for the entire 2016-17 season. A higher number of ascospores (98.7

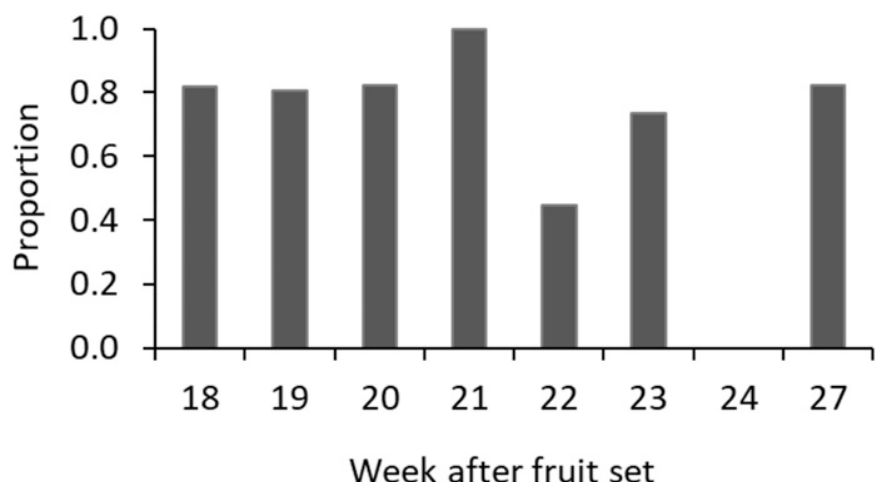

Fig. 3. Relative proportions of Phyllosticta citricarpa present in the total Phyllosticta spp. genomic DNA determined using quantitative PCR (qPCR) for ascospores trapped during sampling weeks 4 to 6,18 to 25, and 27 from fruit set in the 2016-17 season at a Valencia orange (Citrus sinensis) orchard in Mundubbera, Queensland. Spore trap tapes of these weeks had obvious bands of trapped airborne materials; hence, visual spore counts could not be reliably made due to an excess of airborne debris impacting on the tape. qPCR assays for spore trap samples of weeks 4, 5, 6, and 25 detected no Phyllosticta spp. DNA; thus, the results are not presented in this figure.

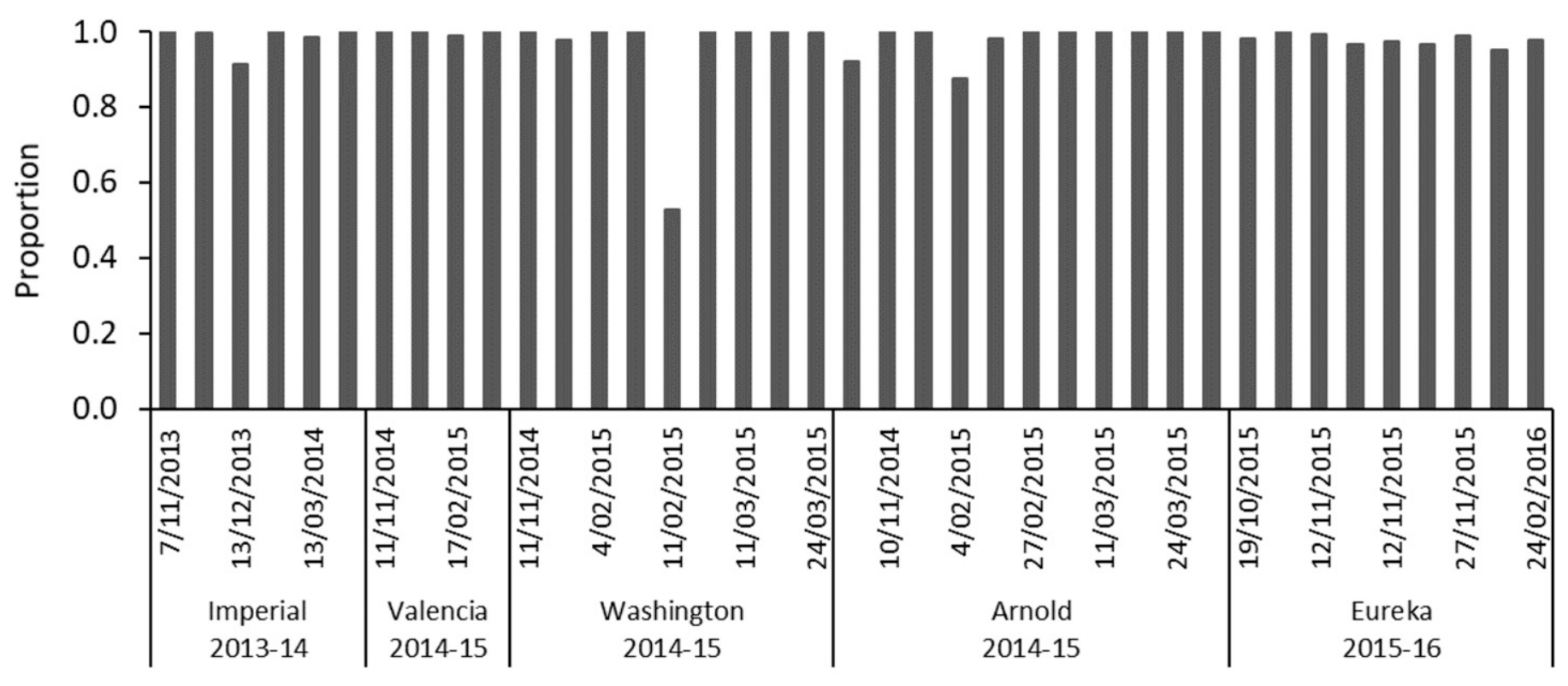

Orchards/Seasons/Sampling dates (dd/mm/yyyy)

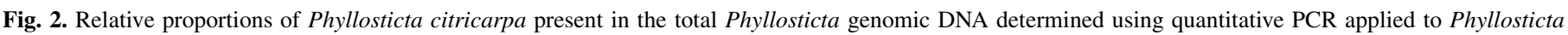

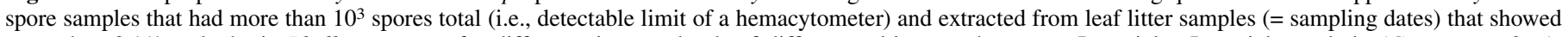

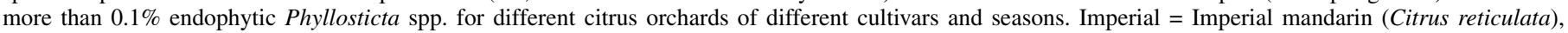

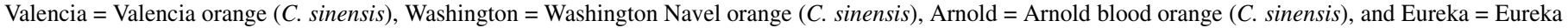
lemon (C. limon). 
ascospores $/ \mathrm{m}^{3}$ ) was captured only during weeks 17 to 20 of the 2015-16 season. Spore trapping studies conducted in different locations-for example, in Brazil (Reis et al. 2006) and South Africa (Fourie et al. 2013)—reported different quantities of Phyllosticta ascospores. In those published studies (Fourie et al. 2013; Reis et al. 2006), the variation in number of ascospores trapped over time within and between seasons was also reported. It should be noted that Reis et al. (2006) and Fourie et al. (2013) used volumetric spore traps with different volumes of 0.3 and 20 liters/ min, respectively. Moreover, the published works only counted portions of the spore trap discs before extrapolating the numbers to the final units whereas, in our study, the entire spore trap tapes were counted because of the observed variability in ascospore count across the tape. It should also be noted that identity of the ascospores trapped was not determined in these previous studies (Fourie et al. 2013; Reis et al. 2006). The large variation in ascospore numbers obtained through spore trapping in field conditions may be affected by several factors, including (i) variability in trapping counts from

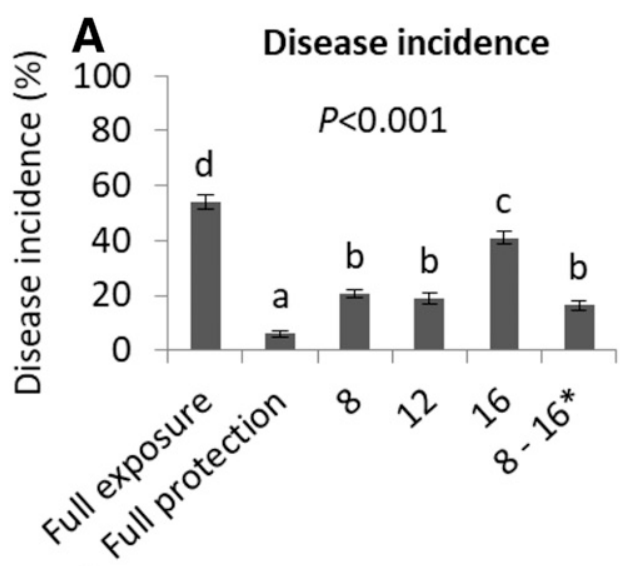

2014-15
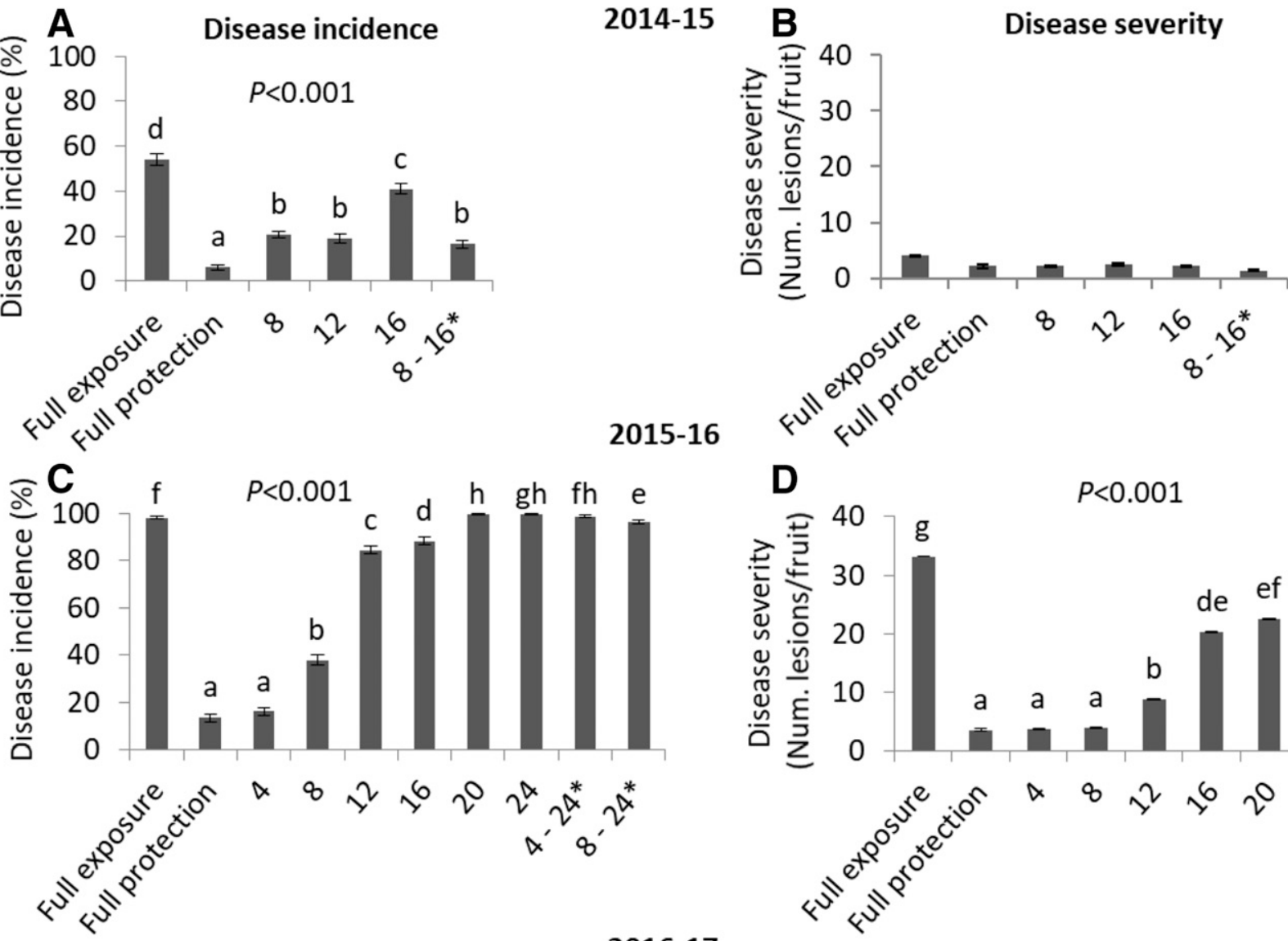

015-16

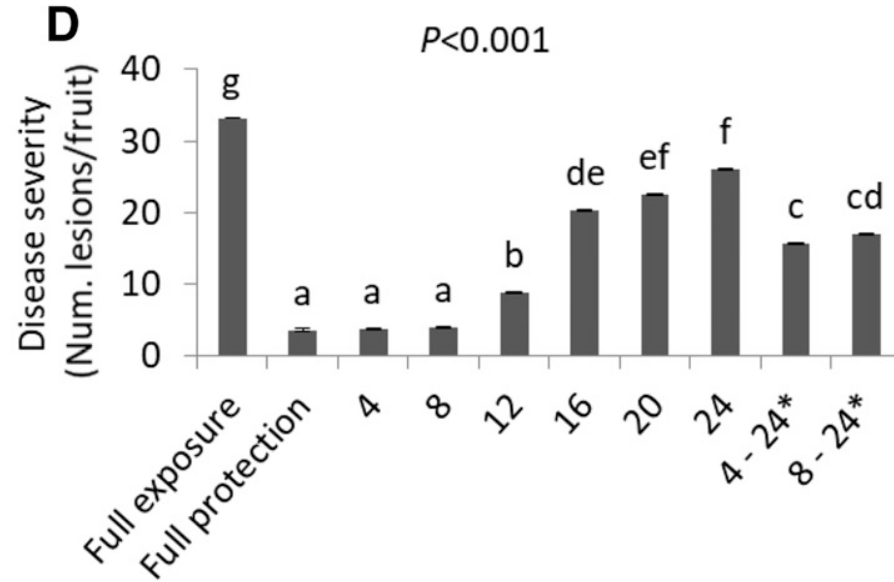

D $\quad P<0.001$

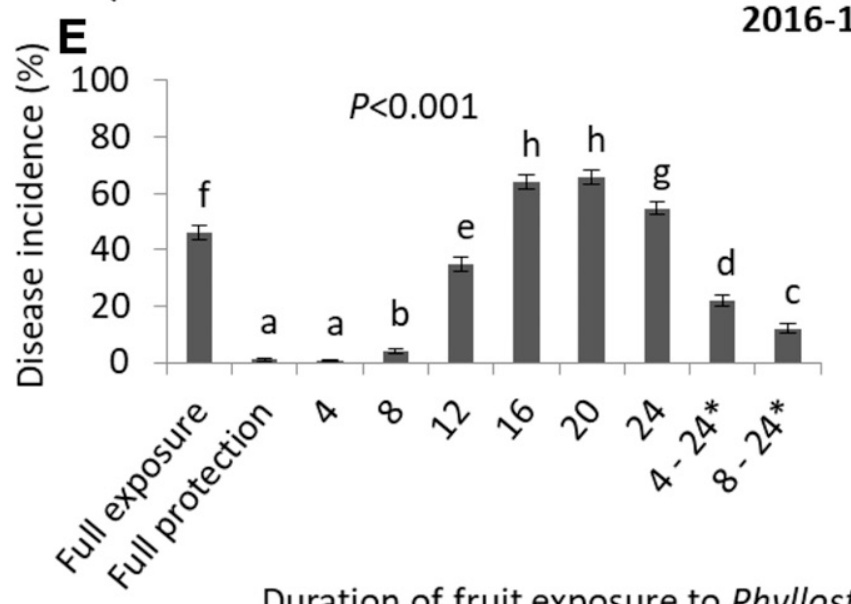

$\mathbf{F}$

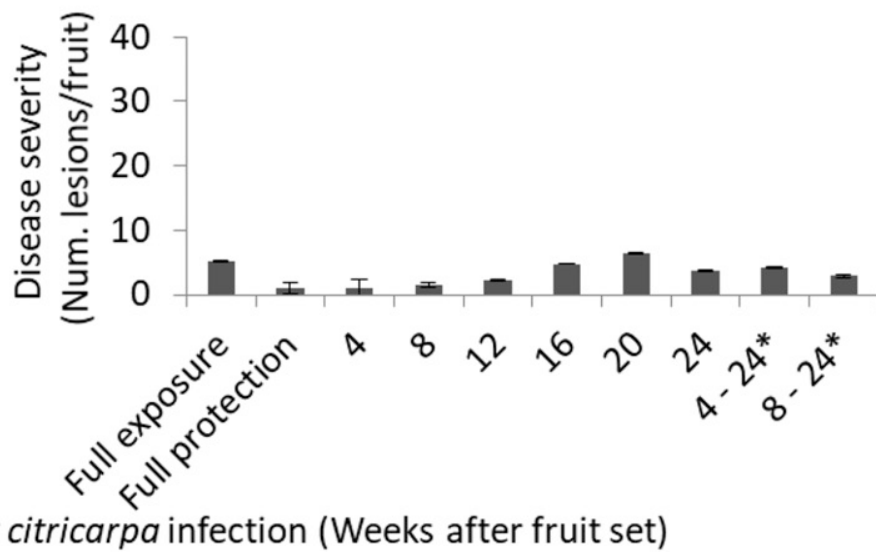

Fig. 4. Citrus black spot $\mathbf{A}, \mathbf{C}$, and $\mathbf{E}$, incidence and $\mathbf{B}, \mathbf{D}$, and $\mathbf{F}$, severity on Arnold blood orange (Citrus sinensis, 2014-15) and Imperial mandarin (C. reticulata, 2015-16 and 2016-17) fruit exposed to natural infection by Phyllosticta citricarpa in Mundubbera, Queensland at different timings of fruit development. Horizontal axes are numbers of weeks after fruit set that the fruit were not sprayed with fungicide to expose them to $P$. citricarpa infection, and are when fungicide was first applied then subsequently reapplied approximately every 4 weeks until week 24 of fruit development to protect them from $P$. citricarpa infection. The experiment in the 2014-15 season was only conducted for 16 weeks of fruit development, and fungicide application starting at week 4 was omitted. Different letters indicate significant difference $(P<0.05)$ using Fisher's least significant difference test; no analysis of variance was performed on disease severity data for the $\mathbf{B}$, 2014-15 and F, 2016-17 seasons but only the means are presented due to the low number of symptomatic fruit. Bars = standard errors and asterisks $(*)$ indicate that fruit were protected from the start of the season until the indicated time and remained exposed for the rest of the season. 
orchards where multiple Phyllosticta spp. may be present but not readily distinguished from each other prior to the recent availability of molecular identification techniques; (ii) environmental conditions such as relative humidity and temperature that affect mating, ascospore production, maturation, release, and dispersal (Fourie et al. 2013; Magarey et al. 2015); (iii) sampling methods, including capacity, height of the traps placed in the fields, and spore counting (Comtois et al. 1999; Hirst 1952); and (iv) different varieties of citrus that may differentially affect production of spores in orchard conditions. As a result, quantitative comparisons of numbers of ascospores trapped by different research groups in different locations and seasons using different sampling methods are not readily achievable.

The qPCR assays of $\mathrm{Hu}$ et al. (2014) proved to be able to distinguish $P$. citricarpa from both endophytic species $(P$. capitalensis and $P$. paracapitalensis) present in Australia (Miles et al. 2013; Tran et al. 2019). Using the qPCR assays to identify and quantify Phyllosticta spp. present in Queensland citrus orchards, we found that the pathogen $P$. citricarpa was considerably more abundant than the endophytic Phyllosticta spp. P. citricarpa was detected in every leaf litter sample from every time point at every site, whereas the endophytes were only detected in a proportion of samples. Across all sites and seasons, endophytic Phyllosticta spp. were detected in $83 \%$ of leaf litter DNA samples. P. citricarpa was also dominant in conidia harvested from leaf litter. Similarly, qPCR of ascospores obtained by spore trapping showed $P$. citricarpa to be dominant $(>72 \%)$ over the endophytic Phyllosticta spp. in the majority of the samples (six of eight) assayed. The present study is not the first attempt to determine the seasonal dynamics of Phyllosticta in Queensland orchards. However, it is the first to include evidence concerning the identity of the observed fruiting bodies and spores, and the first to determine ascospore seasonal dynamics using both direct leaf litter examination and volumetric spore trapping.

Our timing of infection experiments demonstrated that $P$. citricarpa infection of fruit of the early-season Imperial mandarin occurred until week 20 from fruit set. The midseason Arnold blood orange can be infected until at least week 16; however, the period beyond week 16 was not evaluated and, thus, requires further investigation as to whether fruit of this cultivar remain susceptible to $P$. citricarpa for a longer time period. The majority of infections leading to significant development of the disease on Imperial fruit was from weeks 4 to 16 after fruit set, which is from approximately November to January in Queensland. This was evident by the significant increases of disease incidence and severity observed for the consecutive 4-week-long windows of fruit exposure during weeks 4 to 16 . Beyond week 16, exposure of fruit resulted in small or no measurable increase of disease incidence and severity, indicating limited or no infection occurring after this time.

It has been reported that infection of citrus fruit by $P$. citricarpa can occur up to 30 weeks from fruit set but varies between localities and cultivars. For instance, in Brazil, fruit of the late-season varieties Natal and Valencia sweet orange were found to be infected until week 30 (Baldassari et al. 2006; Lanza et al. 2018). Valencia fruit could be infected by $P$. citricarpa until week 28 from fruit set in Ghana (Brentu et al. 2012) or until approximately week 20 in South Africa (McOnie 1964b). The present study showed that timing of $P$. citricarpa infection of the early-season Imperial mandarin is shorter than that reported in the literature for other cultivars.

The variation in the amount of fruit infection by $P$. citricarpa leading to development of citrus black spot may have been due to differences in environmental conditions, inoculum availability, or fruit susceptibility over the fruit season. For example, Kotzé (1981) reported that the critical period of $P$. citricarpa infection occurs between November and January in South Africa. Before November, the fruit is susceptible but the amount of inoculum is low and rains are infrequent, limiting infection; whereas, after January, the weather conditions favor infection but fruit is no longer susceptible
(Kotzé 1981). These factors (Kotzé 1981) could possibly explain the small differences in disease incidence and severity observed before week 4 (November) and after week 16 (January) on Imperial mandarin in the present study. In addition, the remaining petals may have provided some protection to the Imperial fruit from $P$. citricarpa infection during the first 4 weeks of fruit development. Considering the numerous reports of citrus fruit becoming resistant to infection over time (Baldassari et al. 2006; Brentu et al. 2012; Kotzé 1981), the small differences in incidence and severity beyond week 16 could be the result of imperfect protection of fruit by the mancozeb treatments at earlier time points, rather than infection taking place later in the season. Future detailed studies are required to conclusively demonstrate changes in fruit susceptibility over time.

Ascospores have previously been accepted as the primary inoculum source during citrus black spot epidemics (Fourie et al. 2013; Kiely 1948; Kotzé 1981), implying that the majority of infection in the field would coincide with the peak in ascospore and pseudothecium production. However, we found that pseudothecium and ascospore production peaked later in the season and that ascospores produced were less abundant than pycnidia and conidia in leaf litter. The number of ascospores trapped was low during the critical timing of Imperial fruit infection by $P$. citricarpa from weeks 4 to 16 , and peak of ascospore release occurred after the main infection events. Notably, no ascospores were trapped during the period when the majority of infections took place in the 2016-17 season. Moreover, our regression analyses showed no significant correlation between the number of ascospores trapped and disease incidence. Importantly, the overall dominance of $P$. citricarpa in orchards suggests the presence of the endophytic Phyllosticta spp. is unlikely to be an important source of confusion in relating our inoculum data to citrus black spot epidemics in commercial orchards in Queensland. This, however, may not be the case in different environmental conditions.

To build biological relevance around our spore trap data, we calculated the numbers of ascospores required to cause all the lesions observed on fruit in our field trials to compare with the numbers of ascospores trapped. The results showed that numbers of available ascospores were $<2.6 \%$ of those theoretically required. Taking the possible inaccuracies of spore traps into account, we considered another scenario where the spore trap was assumed to operate with an efficiency of $60 \%$ (Hirst 1952) and counting efficiency of $70 \%$ (Comtois et al. 1999). Even then, the proportion of ascospores trapped was not sufficient, with the peak of ascospore release representing only $6.2 \%$ of that theoretically required (data not shown). It is of note that the common inaccuracy of volumetric spore traps is perhaps generally accepted because they were not discussed in past studies (Fourie et al. 2013; Reis et al. 2006). We also need to consider that the spore trap is fixed at a single height of $0.5 \mathrm{~m}$ whereas the fruit is distributed over a much greater vertical range, where increased height from the orchard floor would most likely result in lower spore counts as the distance from their source increases. Additionally, it is unlikely that every ascospore trapped would be viable, or that the prevailing conditions would be uniformly favorable for infection during the entire period when fruit are susceptible, as we assumed for our calculations. As a result, a smaller number of ascospores than those trapped would actually infect fruit leading to disease. Similarly, Fall et al. (2015) found that, in growth chamber conditions, Bremia lactucae at 1 conidium $/ \mathrm{m}^{3}$ was sufficient to cause 1 lesion of downy mildew per lettuce leaf; whereas, in field conditions, 14 conidia/ $\mathrm{m}^{3}$ was required to cause 1 lesion/leaf. Hence, there is insufficient evidence from the present study to conclude that ascospores were the major source of inoculum during the epidemics we have studied on Imperial mandarin in Queensland subtropical conditions. Our finding is contrary to the epidemiological role assigned to ascospores from other areas such as coastal New South Wales (Australia) (Kiely 1948) and South Africa (Fourie et al. 2013), which may be due to 
different citrus cultivars studied in different environmental conditions. Nevertheless, our findings on the role of ascospores should be carefully considered. Further research on the infection efficiency of ascospores and potential contribution of other inoculum sources, particularly those within the tree canopy, will be required to confirm the role of ascospores in Queensland conditions. The assumption that one discrete lesion results from infection by one spore, and the question of whether virulent spot is a result of one or several infections of $P$. citricarpa, also warrant experimental validation.

Because our observations that leaf-litter-derived inoculum and trapped ascospores do not explain the observed level of disease, we hypothesize that additional inoculum sources in the tree canopy play an important role in citrus black spot epidemics. This observation is supported by citrus black spot in Florida, whereby epidemics are progressing in the absence of ascospores due to the presence of only one mating type of P. citricarpa (Hendricks et al. 2020; Wang et al. 2016). Although we confirmed an abundance of conidia in leaf litter, we found no significant correlations between leaf litter conidium production and disease incidence. However, conidia have also been reported to be formed on other parts of the trees, including symptomatic fruit, leaves, twigs, petioles, and thorns (Baldassari et al. 2006; Spósito et al. 2011). Conidia are thought to be limited in the tree canopy, where removal of mature diseased fruit occurs before new fruit set (Spósito et al. 2008, 2011), such as in most citrus varieties grown in Queensland. Solomon et al. (2019) reported that $P$. citricarpa inoculum on dead twigs in the tree canopy was positively correlated with black spot severity, and that dead twigs are an important source of inoculum in Florida. In Brazil, de Oliveira Silva et al. (2017) found that living twigs were colonized by $P$. citricarpa and, thus, could be a reservoir for the pathogen. $P$. citricarpa may exhibit a similar lifestyle in Queensland, with pycnidia possibly occurring in more challenging plant substrates for direct observation such as bark, as proposed by McOnie (1965), whereby latent infection of $P$. citricarpa in citrus twigs is a source of inoculum for fruit infection. A similar etiology has been reported for citrus melanose, caused by Diaporthe citri, in that conidia produced on dead twigs in the canopy serve as a major source of inoculum, while ascospores are produced in relatively small numbers on leaf litter and play a less important role than conidia produced in the canopy (Gopal et al. 2014). The importance of nonleaf-litter sources of $P$. citricarpa inoculum in the subtropical citrus production areas of Australia needs further investigation.

Our findings of the critical period of Imperial fruit infection by $P$. citricarpa from week 4 to 16 , and the improved understanding of the seasonal dynamics of $P$. citricarpa reproductive structures and their relationships with fruit infection, may improve management of citrus black spot in Queensland subtropical conditions. Current fungicide programs to protect fruit from $P$. citricarpa infection involve application of protectant fungicides approximately every 4 weeks, leading to up to eight applications for the 30-week-long period of $P$. citricarpa infection identified previously (Brentu et al. 2012; Lanza et al. 2018; Schutte et al. 2003). Our results demonstrate that only four fungicide applications at 4-week-long intervals during the first 16 weeks after fruit set of Imperial mandarin significantly reduce $P$. citricarpa infection in Queensland. In addition, reduction in disease incidence and severity resulting from one (at fruit set) and two (at fruit set and week 4) fungicide applications indicated the importance of early protection of Imperial fruit from infection by $P$. citricarpa. Our study also shows that the timing of $P$. citricarpa ascospore release may not be a reliable predictor for risk of fruit infection in the field. Thus, modeling or predicting the onset of ascospore release in leaf litter to schedule fungicide application is unlikely to be a successful approach in our local conditions. Instead, detailed investigations of the environmental conditions for infection, the duration of fruit susceptibility, and inoculum sources other than those in leaf litter may identify other disease predictors for improved timing of disease management.

\section{ACKNOWLEDGMENTS}

We thank M. Trott, G. Parr, and C. Robinson for the use of their orchards; T. Wernecke and the Bugs for Bugs team for their help and the use of their facilities; M. Wallis and the Citricare team for their assistance with servicing the spore trap; R. Magarey (Sugar Research Australia) for the loan of the spore trap; G. R. Stirling and A. M. Stirling for use of their facilities; M. M. Dewdney and the team for providing Floridian Phyllosticta DNA; and K. Pegg, A. R. McTaggart, and O. A. Akinsanmi for critically reviewing the manuscript.

\section{LITERATURE CITED}

Alvarez, A. M. 2004. Integrated approaches for detection of plant pathogenic bacteria and diagnosis of bacterial diseases. Annu. Rev. Phytopathol. 42: 339-366.

Anonymous. 2019. Climate Data Online (site numbers 061087 and 039066). Australian Government, Bureau of Meteorology. http://www.bom.gov.au/ climate/data/

Baayen, R. P., Bonants, P. J. M., Verkley, G., Carroll, G. C., van der Aa, H. A., de Weerdt, M., van Brouwershaven, I. R., Schutte, G. C., Maccheroni, W., de Blanco, C. G., and Azevedo, J. L. 2002. Nonpathogenic isolates of the citrus black spot fungus, Guignardia citricarpa, identified as a cosmopolitan endophyte of woody plants, G. mangiferae (Phyllosticta capitalensis). Phytopathology 92:464-477.

Baldassari, R. B., Reis, R. F., and de Goes, A. 2006. Susceptibility of fruits of the 'Valencia' and 'Natal' sweet orange varieties to Guignardia citricarpa and the influence of the coexistence of healthy and symptomatic fruits. Fitopatol. Bras. 31:337-341.

Benson, A. H. 1895. Black spot of the orange. Agric. Gaz. N. S. W. 6:249-251.

Brentu, F. C., Oduro, K. A., Offei, S. K., Odamtten, G. T., Vicent, A., Peres, N. A., and Timmer, L. W. 2012. Crop loss, aetiology, and epidemiology of citrus black spot in Ghana. Eur. J. Plant Pathol. 133:657-670.

Brodrick, C. J., and Rabie, H. R. 1970. Light and temperature effects on symptom development and sporulation of Guignardia citricarpa Kiely, on Citrus sinensis (Linn.) Osbeck. Phytophylactica 2:157-164.

Carstens, E., Linde, C., Slabbert, R., Miles, A. K., Donovan, N., Li, H. Y., Zhang, K., Dewdney, M. M., Rollins, J. A., Glienke, C., Schutte, G. C., Fourie, P., and McLeod, A. 2017. A global perspective on the population structure and reproductive system of Phyllosticta citricarpa. Phytopathology 107:758-768.

Comtois, P., Alcazar, P., and Néron, D. 1999. Pollen counts statistics and its relevance to precision. Aerobiologia 15:19-28.

Cunningham, G. P., and Harden, J. 1998. Reducing spray volumes applied to mature citrus trees. Crop Prot. 17:289-292.

de Oliveira Silva, A., Savi, D. C., Raiser, P. H. S., Gonçalves, F. P., Kava, V., Galli-Terasawa, L. V., and Glienke, C. 2017. Epidemiological aspects of Phyllosticta citricarpa colonization and viability in Citrus sinensis. J. Plant Dis. Prot. 124:73-80.

Erixckson, L. C., and Brannaman, B. L. 1960. Abscission of reproductive structures and leaves of orange trees. Proc. Am. Soc. Hortic. Sci. 75:222-229.

Fall, M., Van der Heyden, H., Beaulieu, C., and Carisse, O. 2015. Bremia lactucae infection efficiency in lettuce is modulated by temperature and leaf wetness duration under Quebec field conditions. Plant Dis. 99:1010-1019.

Fourie, P., Schutte, T., Serfontein, S., and Swart, F. 2013. Modeling the effect of temperature and wetness on Guignardia pseudothecium maturation and ascospore release in citrus orchards. Phytopathology 103:281-292.

Glienke, C., Pereira, O. L., Stringari, D., Fabris, J., Kava-Cordeiro, V., Galli-Terasawa, L., Cunnington, J., Shivas, R. G., Groenewald, J. Z., and Crous, P. W. 2011. Endophytic and pathogenic Phyllosticta species, with reference to those associated with citrus black spot. Persoonia 26:47-56.

Gopal, K., Lakshmi, M., Sarada, G., Nagalakshmi, T., Sankar, T. G., Gopi, V., and Ramana, K. T. V. 2014. Citrus melanose (Diaporthe citri Wolf): A review. Int. J. Curr. Microbiol. Appl. Sci. 3:113-124.

Guarnaccia, V., Groenewald, J. Z., Li, H., Glienke, C., Carstens, E., Hattingh, V., Fourie, P. H., and Crous, P. W. 2017. First report of Phyllosticta citricarpa and description of two new species, $P$. paracapitalensis and P. paracitricarpa, from citrus in Europe. Stud. Mycol. 87:161-185.

Hancock, N. 2014. Page 22 in: Australian Citrus Tree Census 2014. Citrus Australia, Mildura 3502, Victoria, Australia.

Hendricks, K. E., Christman, M. C., and Roberts, P. D. 2020. The effect of weather and location of fruit within the tree on the incidence and severity of citrus black spot on fruit. Sci. Rep. 10:1389.

Hirst, J. M. 1952. An automatic volumetric spore trap. Ann. Appl. Biol. 39: 257-265.

Hofman, H. 2011. Page 146 in: Project report CT04002: Management of Internal Dryness of 'Imperial' Mandarin. Horticulture Australia Limited, Sydney 2000, New South Wales, Australia. 
Hu, J., Johnson, E. G., Wang, N. Y., Davoglio, T., and Dewdney, M. M. 2014. qPCR quantification of pathogenic Guignardia citricarpa and nonpathogenic G. mangiferae in citrus. Plant Dis. 98:112-120.

Kiely, T. B. 1948. Preliminary studies on Guignardia citricarpa, N. SP.: The ascigerous stage of Phoma citricarpa McAlp., and its relation to black spot of citrus. Proc. Linn. Soc. N. S. W. 73:249-292.

Kotzé, J. M. 1981. Epidemiology and control of citrus black spot in South Africa. Plant Dis. 65:945-950.

Lanza, F. E., Metzker, T. G., Vinhas, T., Behlau, F., and Silva, G. J., Junior. 2018. Critical fungicide spray period for citrus black spot control in São Paulo state, Brazil. Plant Dis. 102:334-340.

Magarey, R. D., Hong, S. C., Fourie, P. H., Christie, D. N., Miles, A. K., Schutte, G. C., and Gottwald, T. R. 2015. Prediction of Phyllosticta citricarpa using an hourly infection model and validation with prevalence data from South Africa and Australia. Crop Prot. 75:104-114.

McOnie, K. C. 1964a. Latent occurrence in Citrus and other hosts of Guignardia easily confused with $G$. citricarpa citrus black spot pathogen. Phytopathology 54:40-43.

McOnie, K. C. 1964b. Source of inoculum of Guignardia citricarpa, the citrus black spot pathogen. Phytopathology 54:64-67.

McOnie, K. C. 1965. Source of infection for black spot of citrus. Citrus J. June:5-9.

McOnie, K. C. 1967. Germination and infection of citrus by ascospores of Guignardia citricarpa in relation to control of black spot. Phytopathology 57:743-746.

Miles, A. K., Tan, Y. P., Tan, M. K., Donovan, N. J., Ghalayini, A., and Drenth, A. 2013. Phyllosticta spp. on cultivated Citrus in Australia. Australas. Plant Pathol. 42:461-467.

Miles, A. K., Willingham, S. L., and Cooke, A. W. 2004. Field evaluation of strobilurins and a plant activator for the control of citrus black spot. Australas. Plant Pathol. 33:371-378.

Miles, A. K., Wyatt, P., Kopittke, R., Eelkema, M., Missenden, B., Hamacek, E., Shivas, M., and Drenth, A. 2008. Integrated disease management of citrus black spot (Guignardia citricarpa Kiely) in Queensland, Australia. Pages 1070-1076 in: Proc. 11th Int. Citrus Congr. X. Deng, J. Xu, S. Lin, and R. Guan, eds. China Agriculture Press, Wuhan, China.

Peel, M. C., Finlayson, B. L., and McMahon, T. A. 2007. Updated world map of the Köppen-Geiger climate classification. Hydrol. Earth Syst. Sci. Discuss. 4:439-473.

Reis, R. F., Timmer, L. W., and de Goes, A. 2006. Effect of temperature, leaf wetness, and rainfall on the production of Guignardia citricarpa ascospores and on black spot severity on sweet orange. Fitopatol. Bras. 31:29-34.

Schubert, T. S., Dewdney, M. M., Peres, N. A., Palm, M. E., Jeyaprakash, A., Sutton, B., Mondal, S. N., Wang, N.-Y., Rascoe, J., and Picton, D. D. 2012. First report of Guignardia citricarpa associated with citrus black spot on sweet orange (Citrus sinensis L. Osbeck) in North America. Plant Dis. 96:1225.

Schutte, G. C., Beeton, K. V., and Kotzé, J. M. 1997. Rind stippling on Valencia oranges by copper fungicides used for control of citrus black spot in South Africa. Plant Dis. 81:851-854.
Schutte, G. C., Mansfield, R. I., Smith, H., and Beeton, K. V. 2003. Application of azoxystrobin for control of benomyl-resistant Guignardia citricarpa on 'Valencia' oranges in South Africa. Plant Dis. 87:784788 .

Smith, D., and Papacek, D. F. 1991. Studies of the predatory mite Amblyseius victoriensis (Acarina: Phytoseiidae) in citrus orchards in south-east Queensland: Control of Tegolophus australis and Phyllocoptruta oleivora (Acarina: Eriophyidae), effect of pesticides, alternative host plants and augmentative release. Exp. Appl. Acarol. 12:195-217.

Solomon, C., Dewdney, M. M., Rollins, J. A., and Wang, N. Y. 2019. Dead twigs: A reservoir for Phyllosticta citricarpa inoculum leading to citrus black spot (CBS). (Abstr.) Phytopathology 109:S2.140.

Spósito, M. B., Amorim, L., Bassanezi, R. B., and Hau, B. 2008. Spatial pattern of black spot incidence within citrus trees related to disease severity and pathogen dispersal. Plant Pathol. 57:103-108.

Spósito, M. B., Amorim, L., Bassanezi, R. B., Yamamoto, P. T., Felippe, M. R., and Czermainski, A. B. C. 2011. Relative importance of inoculum sources of Guignardia citricarpa on the citrus black spot epidemic in Brazil. Crop Prot. 30:1546-1552.

Spósito, M. B., Amorim, L., Ribeiro, P. J., Jr., Bassanezi, R. B., and Krainski, E. T. 2007. Spatial pattern of trees affected by black spot in citrus groves in Brazil. Plant Dis. 91:36-40.

Sutton, B., and Waterston, J. 1966. Guignardia citricarpa. In: CMI Descriptions of Plant Pathogenic Fungi and Bacteria, Number 85. CAB International, Wallingford, U.K.

Tran, N. T., Miles, A. K., Dietzgen, R. G., Dewdney, M. M., Zhang, K., Rollins, J. A., and Drenth, A. 2017. Sexual reproduction in the citrus black spot pathogen, Phyllosticta citricarpa. Phytopathology 107:732739

Tran, N. T., Miles, A. K., Dietzgen, R. G., and Drenth, A. 2019. Phyllosticta capitalensis and $P$. paracapitalensis are endophytic fungi that show potential to inhibit pathogenic P. citricarpa on citrus. Australas. Plant Pathol. 48:281-296

Tran, N. T., Miles, A. K., Smith, M. W., Dietzgen, R. G., and Drenth, A. 2018. Pathogenicity of Phyllosticta citricarpa ascospores on Citrus spp. Plant Dis. 102:1386-1393

Truter, M., Kotzé, J. M., Janse van Rensberg, T. N., and Korsten, L. 2004. A sampler to determine available Guignardia citricarpa inoculum on citrus leaf litter. Biosyst. Eng. 89:515-519.

VSN. 2013. GenStat for Windows, 16th ed. VSN International, Hemel Hempstead, Oxford, U.K.

Wang, N. Y., Jose, H. T., Dewdney, M. M., Rollins, J. A. 2015. Draft genome sequences of the citrus black spot pathogen Phyllosticta citricarpa and the ubiquitous fungus $P$. capitalensis. https://www.ncbi.nlm.nih.gov/genome/ 17617 and https://www.ncbi.nlm.nih.gov/genome/44391

Wang, N. Y., Zhang, K., Huguet-Tapia, J. C., Rollins, J. A., and Dewdney, M. M. 2016. Mating type and simple sequence repeat markers indicate a clonal population of Phyllosticta citricarpa in Florida. Phytopathology 106: 1300-1310. 